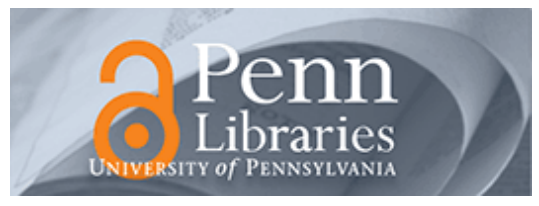

University of Pennsylvania

ScholarlyCommons

Marketing Papers

Wharton Faculty Research

$9-2006$

\title{
Extending the Bounds of Rationality: Evidence and Theories of Preferential Choice
}

Jörg Rieskamp

Jerome R. Busemeyer

Barbara Mellers

University of Pennsylvania

Follow this and additional works at: https://repository.upenn.edu/marketing_papers

Part of the Behavioral Economics Commons, Cognition and Perception Commons, Cognitive Psychology Commons, and the Marketing Commons

\section{Recommended Citation}

Rieskamp, J., Busemeyer, J. R., \& Mellers, B. (2006). Extending the Bounds of Rationality: Evidence and Theories of Preferential Choice. Journal of Economic Literature, 44 (3), 631-661. http://dx.doi.org/ 10.1257/jel.44.3.631

This paper is posted at ScholarlyCommons. https://repository.upenn.edu/marketing_papers/414

For more information, please contact repository@pobox.upenn.edu. 


\title{
Extending the Bounds of Rationality: Evidence and Theories of Preferential Choice
}

\author{
Abstract \\ Most economists define rationality in terms of consistency principles. These principles place "bounds" on \\ rationality-bounds that range from perfect consistency to weak stochastic transitivity. Several decades \\ of research on preferential choice has demonstrated how and when people violate these bounds. Many of \\ these violations are interconnected and reflect systematic behavioral principles. We discuss the \\ robustness of thes violations and review the theories that are able to predict them. We further discuss the \\ adaptive functions of the violations. From this perspective, choices do more than reveal preferences; they \\ also reflect subtle, yet often quite reasonable, dependencies on the environment. \\ Disciplines \\ Behavioral Economics | Business | Cognition and Perception | Cognitive Psychology | Marketing
}




\title{
Extending the Bounds of Rationality: Evidence and Theories of Preferential Choice
}

\author{
Jörg Rieskamp, Jerome R. Busemeyer, and Barbara A. Mellers*
}

\begin{abstract}
Most economists define rationality in terms of consistency principles. These principles place "bounds" on rationality - bounds that range from perfect consistency to weak stochastic transitivity. Several decades of research on preferential choice has demonstrated how and when people violate these bounds. Many of these violations are interconnected and reflect systematic behavioral principles. We discuss the robustness of the violations and review the theories that are able to predict them. We further discuss the adaptive functions of the violations. From this perspective, choices do more than reveal preferences; they also reflect subtle, yet often quite reasonable, dependencies on the environment.
\end{abstract}

\section{Introduction}

$\mathrm{P}$ references are inherently subjective and arise from a mixture of aspirations, thoughts, motives, emotions, beliefs, and desires. This inherent subjectivity means that preferences are not easily evaluated against objective criteria without knowledge of an individual's goals. For example, it is impossible to know whether an individual's

\footnotetext{
* Rieskamp: Max Planck Institute for Human Development, Berlin, Germany. Busemeyer: Indiana University. Mellers: University of California, Berkeley. We gratefully acknowledge helpful comments on previous versions of this article by Claudia Gonzalez-Vallejo, Mark J. Machina, Anthony A. Marley, and Peter P. Wakker. We also thank Donna Alexander for editing a draft of this article. The second author was partially supported by the China Europe International Business School and by NSF SES0083511 awarded to Indiana University, Bloomington, and the third author was partially supported by NSF SES0111944 awarded to the University of California, Berkeley.
}

preference for chocolate over vanilla ice cream is "rational" without knowing the attitudes, values, perceptions, beliefs, and goals of that individual. For this reason, most theorists evaluate the rationality of behavior using principles of consistency and coherence within a system of preferences and beliefs.

The view that rationality only refers to internal coherence and logical consistency has been sharply criticized on multiple grounds. Many have argued (e.g., Gerd Gigerenzer 1996a) that consistency principles are insufficient for defining rationality. If the achievement of an individual's goal does not imply consistency, it is questionable whether functional behavior that violates consistency principles should be called "irrational." In addition, people are imperfect information processors and limited in both knowledge and computational capacity. 


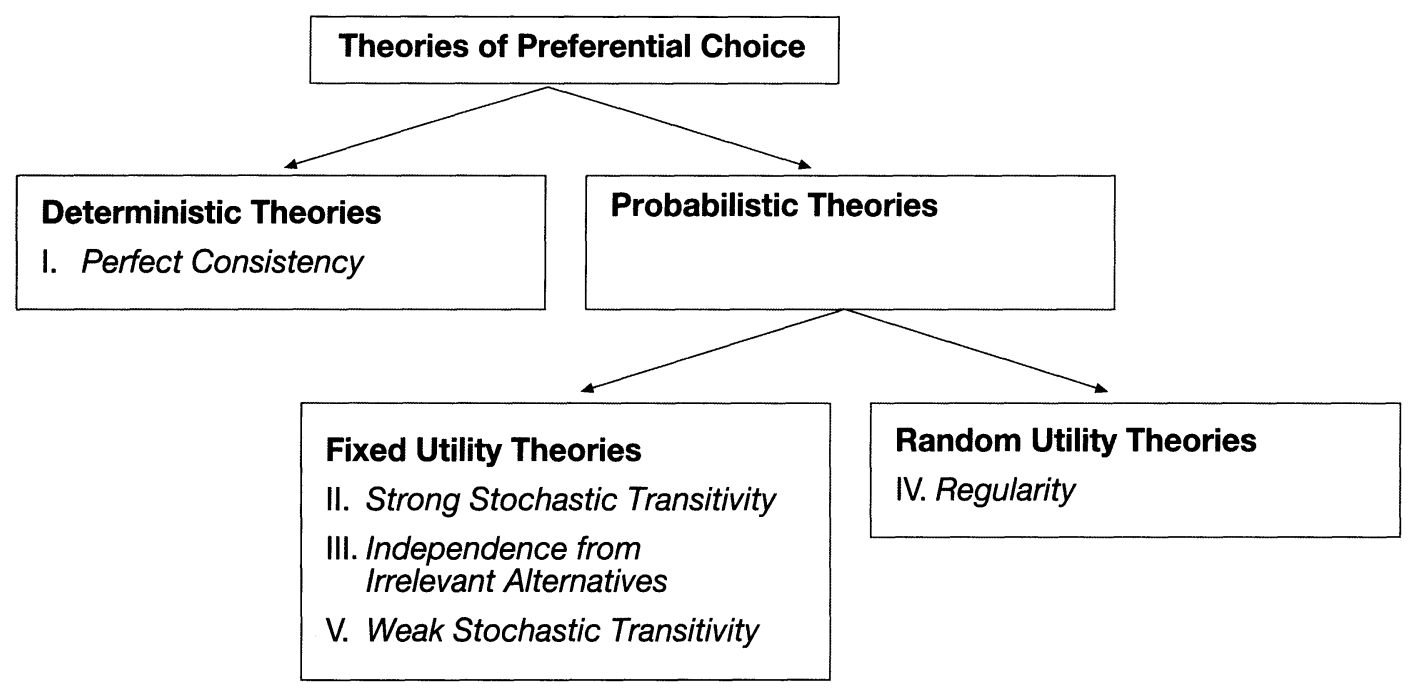

Figure 1. Five Consistency Principles and Their Relatedness

Herbert A. Simon $(1956,1983)$ and others (Gigerenzer and Reinhard Selten 2001) use the term bounded rationality to describe human behavior. Consistency violations might well be adaptive when time, knowledge, or resources are scarce (e.g., Robert J. Aumann 1962; Mark J. Machina 1982; Michele Cohen and Jean-Yves Jaffray 1988; Gigerenzer 1991, 1996b; Lola L. Lopes and Gregg C. Oden 1991; Kenneth R. Hammond 1996; Lopes 1996; Philippe Mongin 2000).

Several decades of research on preferential choice has led to an impressive body of empirical knowledge on how and when people violate consistency principles of preferential choice. The purpose of this article is to review these basic facts. Our review differs from previous reviews (e.g., Paul J. H. Schoemaker 1982; Chris Starmer 2000) in terms of the consistency principles we examine. Previous reviews focused primarily on consistency across operations applied to properties of choice objects. For example, the independence axiom of expected utility theory requires consistency across linear transformations of probabilities and thus is restricted to the domain of decisions under risk. In contrast, we are interested in consistency principles that go beyond assumptions about the properties or attributes of the choice objects. For example, the transitivity axiom is applicable to a wide range of choice objects, including both risky gambles as well as risk free commodity bundles.

We organize our paper around five consistency principles that are summarized in figure 1. Each principle helps to define a class of theories. The principles differ in type (logically independent principles-one principle does not imply anything about another), and strength (logically dependent principles-a stronger principle implies a weaker one). The principles have been labeled from I to V, but they only allow a partial ordering of constraints.

The first principle is perfect consistency or invariant preferences across occasions. Perfect consistency implies the other four principles. The second principle, strong stochastic transitivity, is logically equivalent to the third principle, independence from irrelevant alternatives (Amos Tversky and Edward J. Russo 1969). Regularity is the fourth principle, but there is no logical connection between independence from irrelevant alternatives and regularity (one does not logically imply the other). Independence 
from irrelevant alternatives implies the fifth principle of weak stochastic transitivity.

A primary goal of this paper is to assess the degree to which preferential choices obey the principles. For each principle, we summarize the empirical evidence. When are the violations serious and robust? When are they small or limited? By evaluating the types of violations and the magnitude of those violations, we can determine which principles must be relaxed in descriptive theories of preferential choice. Furthermore, we show that many violations are related and suggest some underlying behavioral regularities that should be addressed in a general descriptive theory.

A secondary goal is to discuss theories of preferential choice in terms of the consistency principles. We will review classes of theories and discuss their compliance or lack of compliance with the five consistency principles. When evaluating the different theories, we will consider the extent to which they can describe empirical violations of the consistency principles. We will also consider the complexity of the theories. Selten (1991) argued that, if two models are equally successful in predicting existing data, the parsimonious model that, in principle, is only able to predict a small range of data should be preferred over the more complex model that, a priori, can predict a larger range of data. In a similar vein, Mark Pitt, In Jae Myung, and Shaobo Zhang (2002) have argued that a model's generalizability, or the ability of the model to predict independent new data, is essential to model selection. A complex model might be superior to a simpler model when fitting observed behavior, but, due to the danger of overfitting, the complex model might be predicting noise rather than systematic regularities and, therefore, is less suitable for predicting new independent behavior.

A third goal of this paper is to step back and reconsider the meaning of rationality. We discuss the advantages and disadvantages of each principle from different perspectives and address the question of how far the bounds of rationality must be pushed to accommodate basic and systematic regularities in human choice.

\section{Perfect Consistency}

The standard utility theory of preference begins by positing a choice set, $X=\{A, B$, $C, \ldots\}$, with elements, $A, B$, and $C$, denoting the options. The choice might involve meals, movies, or mutual funds. A preference relation, $\geq_{p}$, is defined for all pairs of options, such that $A \geq_{p} B$ means that option $A$ is preferred to option $B$, or that the decisionmaker is indifferent. Finally, a set of axioms is imposed on the preference relations to permit the construction of a utility function $u: X \rightarrow R$. The utility function assigns a real-valued utility to each option (e.g., $u(A)$ is the utility assigned to option $A$ ), and the order implied by the utilities is used to predict the empirical preference ordering, that is, $u(A) \geq u(B)$ if, and only if $A \geq_{\mathrm{p}} B$.

Standard utility theories include the expected utility theory (John von Neumann and Oskar Morgenstern 1947), rankdependent utility theories (e.g., John Quiggin 1982; Chew Soo Hong, Edi Karni, and Zvi Safra 1987; Menahem E. Yaari 1987; Jerry R. Green and Bruno Jullien 1989; R. Duncan Luce 1990), and multiattribute utility theories (Ralph L. Keeney and Howard Raiffa 1976; Detlof von Winterfeldt and Ward Edwards 1986). All such theories are based on the axiom of transitivity. Transitivity states that for any triad of options, $A, B$, and $C$, if two preferences hold, $A \geq_{\mathrm{p}} B$ and $B \geq_{\mathrm{p}} C$, then a third one should follow, $A \geq_{\mathrm{p}} C$. This axiom is a cornerstone of normative and descriptive theories because it implies that the utilities can be represented as transitive, real numbers (Paul Samuelson 1953; Edwards 1954, 1961).

To test this axiom, one must measure preferences. There are at least two commonly used methods to "elicit" preferences-one based on choices and the other based on 
judged prices, typically referred to as certainty equivalents. Unfortunately, these methods do not always agree. For example, when presented with a choice between two gambles, $A$ and $B$, individuals may prefer gamble $A$ on the basis of choice, but state a higher price for gamble $B$ (for reviews, see David M. Grether and Charles R. Plott 1979; Paul Slovic and Sarah Lichtenstein 1983; Tversky, Slovic, and Daniel Kahneman 1990; Barbara A. Mellers, Shi-Jie Chang, Michael H. Birnbaum, and Lisa D. Ordonez 1992). The psychological reasons for different preferences obtained with different response modes are controversial, and there is no real consensus about which method is better. Both methods of eliciting preferences have pros and cons. Nonetheless, many researchers prefer to use choices, and for this reason, we focus on choice ${ }^{1}$ (for an alternative perspective, see Luce, Mellers, and Chang 1993).

Differences in measured preferences occur not only across methods but also across occasions within an individual. In a classic study, Frederick Mosteller and Philip Nogee (1951) demonstrated that individuals were often inconsistent in their preferences for simple gambles over repeated occasions. Participants were asked to accept or reject binary gambles with fixed-outcome probabilities and increasing amounts to win. The tendency for an individual to select the gamble did not suddenly jump from zero to one at an acceptable winning payoff. Instead, acceptance frequencies were a smooth Sshaped function when plotted against the winning amount. The preference function was strikingly similar to a psychometric function, such as those derived from the discrimination of stimuli along psychophysical continuua, such as loudness, heaviness, and brightness. More recent evidence shows that

\footnotetext{
${ }^{1}$ It is reasonable to assume that when a decisionmaker states his or her price or certainty equivalent for an option, he or she will often cognitively perform a series of comparisons between the option and candidate prices, although these comparisons are not indispensable.
}

participants typically change their minds in approximately 25 percent of choice pairs (approximately equal in expected value but differing in risk) that are presented twice (Colin F. Camerer 1989; John D. Hey and Chris Orme 1994; Peter Wakker, Ido Erev, and Elke U. Weber 1994; T. Parker Ballinger and Nathaniel T. Wilcox 1997; Jerome R. Busemeyer, Ethan Weg, Rachel Barkan, Xuyang Li, and Zhengping Ma 2000).

In an extensive study of choice consistency, Hey (2001) asked participants to make one hundred choices between pairs of gambles that were repeated in five sessions. Participants were paid according to the outcome of the chosen gamble. Overall rates of inconsistencies varied greatly across participants, ranging from 1 percent to 21 percent. On average, participants changed their choices 11 percent of the time from the first to the second session. Not a single participant had consistent preferences across the first two sessions, while rates of inconsistency decreased slightly. Participants reversed their choices 9 percent of the time from the fourth to the fifth session. ${ }^{2}$ Virtually all of the participants were inconsistent throughout the entire experiment. Only one of the fiftythree participants made identical choices in the last three sessions.

In sum, we have crossed the first bound of rationality. The literature is replete with choice variability over time, contexts, and occasions. To accommodate these results and those of many other studies, we must relax the assumption that choices are deterministic, and accept the inherent variability of preferences.

\section{Strong Stochastic Transitivity}

We now turn to probabilistic theories of choice (for an overview, see Anthony A. J.

\footnotetext{
${ }^{2}$ Note, however, that in Hey (2001) participants were forced to select one gamble out of the pairs instead of also allowing expressions of indifference. Thereby, inconsistent choices do not necessarily represent systematic or unsystematic inconsistencies, but could be due to indifferences between particular gambles.
} 
Marley 1992). These theories posit the existence of a function that maps choice pairs into probabilities. Hereafter, $p(A \mid\{A, B\})$ denotes the probability of choosing $A$ from the set $A$ and $B$. Choice probabilities are often estimated by presenting an individual with the same choice on multiple occasions (with other problems interwoven between repetitions). Weak probabilistic choice theories imply that either $A$ is preferred to $B$ if, and only if, $p(A \mid\{A, B\})>.50$, or $B$ is preferred to $A$ if, and only if, $p(B \mid\{A, B\})>.50$ (indifference holds in the very rare case that $p(A \mid\{A, B\})=.50$; for a review, see Luce 2000). Strong probabilistic choice theories make precise predictions about the probability mass of each option in the set.

There are two classes of strong probabilistic theories-random utility theories and fixed utility theories (see Gordon Becker, Morris H. Degroot, and Jacob Marschak 1963; Luce and Patrick Suppes 1965). According to random utility theories, individuals select the option with the highest utility using a deterministic decision rule and variable utilities that differ over time and contexts (Louis L. Thurstone 1959; Becker, Degroot, and Marschak 1963; Tom Domencich and Daniel L. McFadden 1975; Charles F. Manski 1977; McFadden 1981, 2001; Marley and Hans Colonius 1992; for a review, see Marley 1992). In contrast, fixed utility theories (also called "simple scalability theories") assume that individuals select the option with the highest utility using a probabilistic decision rule and deterministic utilities. If a theory fulfills the property of simple scalability, each option in a choice set can be assigned a scale value such that the choice probabilities are a monotone function of the scale values of the options (Tversky 1972a). A third approach assumes that both the utilities and the decision process are deterministic, but choices are based on randomly selected strategies (see, e.g., Machina 1985; John W. Payne, James R. Bettman, and Eric J. Johnson 1993; Graham Loomes and Robert Sugden 1995; Jörg Rieskamp and
Philipp E. Otto 2006). However, this approach has not addressed the phenomena reviewed in this article.

Random utility theories, representing the first class of strong probabilistic choice theories, are defined as follows: Given a set of $n$ options, each option, $A_{i}$, is assigned a random utility $U\left(A_{i}\right)$, defined by a single joint distribution function for all choice sets. ${ }^{3}$ Option $A_{i}$ is always chosen when it has the highest utility of the available options, and its choice probability is:

$$
\begin{gathered}
p\left(A_{i}\right)=p\left[U\left(A_{i}\right)>\mathrm{U}\left(A_{j}\right)\right], \\
\text { for all } j=1,2, \ldots, n, j \neq i .
\end{gathered}
$$

A simplifying assumption commonly used in conjunction with standard random utility models is that the utility of an option can be expressed as

$$
U\left(A_{i}\right)=\sum_{k} \beta_{k} \cdot x_{i k}+\varepsilon_{i},
$$

where $x$ are the $k$ attributes of the options, $\beta$ are the weights assigned to the attributes, and $\varepsilon$ is an error. Random utility models tend to differ according to the assumptions made about the errors. If it is assumed that the error component is identically and independently distributed following an extreme value distribution, the multinomial logit model results, which is the most common random utility choice model (Kenneth E. Train 2003, for an overview see McFadden 2001). According to this model, the probability that option $A_{i}$ is chosen is defined as:

$$
p\left(A_{i}\right)=\frac{\exp \left(\sum_{k} \beta_{k} \cdot x_{i k}\right)}{\sum_{j=1}^{n} \exp \left(\sum_{k} \beta_{k} \cdot x_{j k}\right)},
$$

\footnotetext{
${ }^{3}$ More formally, assume that $X$ is a complete set of options and $Y$ is a subset of $X(Y \subseteq X)$, that is $Y=\left\{A_{1}, \ldots, A_{m}\right\}$ and $X=\left\{A_{1}, \ldots, A_{n}\right\}$ with $n \geq m$. Define $U_{X}=\left[U_{1}, U_{2}, \ldots, U_{n}\right]$ as a random utility vector with the probability distribution function $F\left(u_{1}, \ldots, u_{n}\right)=F(\mathbf{u})$ and density $f\left(u_{1}, \ldots, u_{n}\right)=f(\mathbf{u})$. Then $p\left(A_{i} \mid Y\right)$ equals the probability of sampling a random utility vector $U_{X}$ within the set $\Delta_{i}=\left\{\mathbf{u} \in \mathbf{R}^{n} \mid u_{i} \geq u_{\text {j }}\right.$ for $j=1, \ldots, m\}$. This probability equals the integral of the distribution within the region $\Delta_{\mathrm{i}}$ :

$$
p\left(A_{i} \mid Y\right)=\int_{\Delta_{i}} d F(\mathbf{u})=\int_{\Delta_{i}} f(\mathbf{u}) d \mathbf{u} .
$$
}


where $x$ and $\beta$ are defined in equation 2. The key assumption of the model is the independent error component, which implies that the alternatives' utilities are also independent.

Fixed utility theories, representing the second class of strong probabilistic choice theories, are probabilistic extensions of deterministic utility theories that share a property known as "simple scalability" (Becker, Degroot, and Marschak 1963; Luce and Suppes 1965; Tversky 1972a). Fixed utility theories imply that a single scale value can be assigned to each option in a complete set of options and that this value will be independent of the other options in the choice set presented. For example, $u(A)$ and $u(B)$ can be real numbers that represent the utilities of options $A$ and $B$. The choice probability for an arbitrary pair of options is determined by means of a function, $F$, ranging from zero to one, where:

$$
p(A \mid\{A, B\})=F[u(A), u(B)] .
$$

$F$ is strictly increasing in the first argument and strictly decreasing in the second, and $F[u(A), u(B)]=.50$ when $u(A)=u(B)$. All simple fixed utility theories imply strong stochastic transitivity, which is a natural extension of the deterministic axiom of transitivity (see Edwards 1961).

The consistency principle of strong stochastic transitivity states that for any arbitrary triplet of options, $A, B$, and $C$ :

$$
\begin{gathered}
\text { If } p(A \mid\{A, B\}) \geq .50 \text { and } p(B \mid\{B, C\}) \geq .50, \\
\text { then } p(A \mid\{A, C\}) \geq \max \{p(A \mid\{A, B\}), \\
p(B \mid\{B, C\})\} .
\end{gathered}
$$

The first condition, $p(A \mid\{A, B\}) \geq .50$, implies that $u(A) \geq u(B)$. The second condition, $p(B \mid\{B, C\}) \geq .50$, implies that $u(B) \geq u(C)$. By the transitivity of real numbers, $u(A) \geq u(C)$, the first consequence, $p(A \mid\{A, C\}) \geq p(A \mid\{A, B\})$, follows from $u(B) \geq u(C)$ and the assumption that $F$ is a decreasing function of the second argument. The second consequence, $p(A \mid\{A, C\}) \geq p(B \mid\{B, C\})$, follows from
$u(A) \geq u(B)$ and the assumption that $F$ is an increasing function of the first argument. The class of fixed utility theories includes Luce's (1959) choice model and many more recent theories. Although not all random utility theories do, Thurstone's (1927) Case V model and the multinominal logit model described above also imply strong stochastic transitivity (for proofs, see Luce and Suppes 1965). For a review, see Hey and Orme (1994) and David W. Harless and Camerer (1994).

Does human choice behavior obey the principle of strong stochastic transitivity? An overwhelming number of studies suggest otherwise. Many of the original experiments were carried out several decades ago (Clyde H. Coombs 1958; Coombs and Dean G. Pruitt 1961; David H. Krantz 1967; Tversky and Russo 1969; Lennart Sjoberg 1975, 1977; Sjoberg and Dora Capozza 1975). In one study (Coombs and Pruitt 1961), participants were asked to choose between monetary gambles with different variances. In 25 percent of all possible triplets, choices violated strong stochastic transitivity. In another study of choices between gambles with cigarettes as outcomes that were given to the participants, Betty J. Griswold and Luce (1962) found strong stochastic transitivity violations in 26 percent of all triplets. Donald L. Rumelhart and James G. Greeno (1971) presented participants with pairs of celebrities and asked them to select the celebrity with whom they would prefer to have a one-hour conversation. Violations of strong stochastic transitivity appeared in 46 percent of the possible triplets.

Mellers and Karen Biagini (1994) reviewed the literature on strong stochastic transitivity violations and argued that the presence or absence of such violations depends on the comparability of options (Krantz 1967; Tversky and Russo 1969). When people compare multiattribute options, the similarity of values along one attribute enhances differences on other attributes. These comparability effects are easily linked to cognitive processing. When 
evaluating options, people pay more attention to attributes that differ. Consider, for example, two jobs with comparable salaries, but different commuting times. Due to the similarity of salaries, people place greater attention and importance on differences in commuting times.

Comparability effects imply that violations of strong stochastic transitivity should follow a specific predictable pattern. Mellers and Biagini (1994) reanalyzed several data sets and found strong experimental evidence. To illustrate the effect, consider the three gambles shown in table 1 . Gamble $A$ offers a 29 percent chance of winning $\$ 3$, otherwise $\$ 0$, gamble $B$ has a 5 percent chance of winning $\$ 17.50$, otherwise $\$ 0$, and gamble $C$ has a 9 percent chance of winning $\$ 9.70$, otherwise $\$ 0$. Gambles are matched in expected values. Furthermore, gambles $B$ and $C$ have relatively similar levels of probability (i.e., 5 percent and 9 percent). Mellers, Chang, Birnbaum, and Ordonez (1992) found that $A$ was preferred to $B$, $p(A \mid\{A, B\})=.59$, and $B$ was preferred to $C$, $p(B \mid\{B, C\})=.72$. Strong stochastic transitivity implies that the preference for $A$ over $C$ should be at least as high as .72. Instead, $p(A \mid\{A, C\})$, the preference for $A$ over $C$ was only .51 . This finding was observed with and without financial incentives (i.e., paying participants the gambles' outcomes). One could argue that either the preference for $B$ over $C$ was "too strong" or the preference for $A$ over $C$ was "too weak." Mellers and Biagini argued that the similarity of probability levels for gambles $B$ and $C$ ( 5 percent and 9 percent, respectively) increased the perceived differences in payoffs $(\$ 17.50$ and $\$ 9.70$, respectively) making $B$ seem much better than $C{ }^{4}$

Mellers and Biagini (1994) proposed a contrast-weighting model to explain this pattern of strong stochastic transitivity violations.

\footnotetext{
${ }^{4}$ In their paper, Mellers et al. (1992) presented strength of preference judgments, which were converted to choice proportions for this review.
}

Consider a choice between two gambles, where gamble $A$ has some probability, $p_{A}$, of winning $x_{A}$, and gamble $B$ has some probability, $p_{B}$, of winning $x_{B}$. The probability of selecting gamble $A$ over $B$ is the difference between the products of utilities and subjective probabilities as follows:

$$
\begin{gathered}
p(A \mid\{A, B\})= \\
J\left[u\left(x_{A}\right)^{\alpha} s\left(p_{A}\right)^{\beta}-u\left(x_{B}\right)^{\alpha} s\left(p_{B}\right)^{\beta}\right],
\end{gathered}
$$

where $J$ is a response function (e.g., a cumulative logistic function), and $\alpha$ and $\beta$ are weights associated with utilities and subjective probabilities, respectively. The weight associated with the utilities, $\alpha$, depends on the difference between the subjective probabilities (i.e., $s\left(p_{A}\right)-s\left(p_{B}\right)$ ). The bigger the probability difference, the smaller the value of $\alpha$. The same logic holds for $\beta$; the bigger the difference between the utilities, the smaller the weight attached to probabilities. Similar values on one attribute enhance differences on other attributes.

The stochastic difference model (Claudia Gonzalez-Vallejo 2002) is another psychological model that can explain violations of strong stochastic transitivity by assuming that options are compared intradimensionally. For each dimension, the model determines the proportional advantage or disadvantage of an option compared with the other option. For example, if gamble A's outcome is larger than gamble $B$ 's outcome (i.e., $x_{A}>x_{B}$ ), the proportional advantage of gamble $A$ is computed as $\left(x_{A}-x_{B}\right) / x_{A}$. If the winning probability of gamble $A$ is smaller than the winning probability of $B$, this represents a proportional disadvantage defined as $\left(p_{B}-p_{A}\right) / p_{B}$. The disadvantage is subtracted from the advantage providing a proportional difference $d$. The decisionmaker prefers the first option, when $d$ is larger than $(\delta+\varepsilon)$, where $\delta$ is a personal decision threshold parameter and $\varepsilon$ is a normal distributed error with mean zero and a standard deviation, $\sigma$, as a free parameter. 
TABLE 1

Gambles Used by Mellers et al. (1992) to Illustrate Comparability Effects

\begin{tabular}{cccc}
\hline \hline & $A$ & $B$ & $C$ \\
\hline Probability of Winning & .29 & .05 & .09 \\
Amounts to Win & $\$ 3.00$ & $\$ 17.50$ & $\$ 9.70$ \\
\hline
\end{tabular}

\section{Independence from Irrelevant Alternatives}

Another principle implied by fixed utility theories, is the independence from irrelevant alternatives (IIA). This principle states that the relative preference for two options, such as $A$ and $B$, should not vary when each is evaluated with respect to option $C$ or $D$ (see Roy Radner and Marschak 1954; Tversky and Russo 1969; Tversky 1972a). ${ }^{5}$

More formally, this principle states that for any arbitrary quadruple of options, $A, B$, $C$, or $D$, the following property must hold:

$$
\begin{gathered}
\text { If } p(A \mid\{A, C\}) \geq p(B \mid\{B, C\}), \\
\text { then } p(A \mid\{A, D\}) \geq p(B \mid\{B, D\}) .
\end{gathered}
$$

The condition on the left implies that $u(A) \geq u(B)$, and that this order implies the consequence on the right. There is an equivalence relation between strong stochastic transitivity and the IIA. Tversky and Russo (1969) proved that one principle is satisfied if, and only if, the other is satisfied. Tversky (1972a) also proved that the IIA is sufficient for guaranteeing the construction of a fixed utility theory.

There is a stronger version of the IIA principle economists often refer to: According to Luce (1959), this principle states that when having an option set $T$ containing the options $A$ and $B$ the following property must hold:

\footnotetext{
5 Also called "property alpha" by Sen (1993); for an overview of the different notions, see Iain McLean (1995).
}

$$
\frac{p(A \mid\{A, B\})}{p(B \mid\{A, B\})}=\frac{p(A \mid S)}{p(B \mid S)},
$$

where $S$ is any possible subset of $T$ including $A$ and $B$.

This stronger version does not only require that the order of the choice probabilities for $A$ and $B$ be independent, but also that the ratios of the choice probabilities be independent of the option sets.

Psychologists have commonly focused upon testing the weaker and more general version of the IIA principles, which of course implies violations of the stronger independence principle. Violations of the weak version are more remarkable since they represent changes in the order of preferences, whereas violations of the strong version may be caused by only slight changes in the strength of preferences. Therefore the focus of our review is on the weak version. Many studies show that people violate the weaker form of the independence principle. Busemeyer and James T. Townsend (1993) reviewed this literature and argued that these violations were driven by the same comparability effects that lead to violations of strong stochastic transitivity. For example, Busemeyer (1985) investigated the independence axiom in sequential choices between a gamble and a "sure thing." Participants, who were paid according to the gambles' outcomes, had to choose between gambles: There was a lowrisk gamble, $A$, (normally distributed with mean zero and standard deviation $5 \mathrm{c}$ ) and a high-risk gamble, $B$, (normally distributed 
with mean zero and standard deviation $50 \mathrm{c}$ ). There were also two sure things: $C$ was $-1 c$ and $D$ was $1 c$. Participants preferred $A$ to $C$, and $B$ to $C$. Furthermore, $p(A \mid\{A, C\})$ was greater than $p(B \mid\{B, C\})$ (i.e., $p(A \mid\{A, C\})=.75$, and $p(B \mid\{B, C\})=.56)$. According to the independence principle, $p(A \mid\{A, D\})$ should be greater than $p(B \mid\{B, D\})$. However, the opposite order appeared (i.e., $p(A \mid\{A, D\})=.30$, and $p(B \mid\{B, D\})=.50)$.

Busemeyer and Townsend (1993) argued that choice probability between two gambles, $A$ and $B$, is an increasing function of the ratio $d=(u(A)-u(B)) / \sigma$, where the numerator is the expectation of the differences between the random utilities of the gambles, and the denominator is the standard deviation of the differences between the random utilities of the gambles. The standard deviation, $\sigma$, determines how easy or difficult it is to discriminate the mean difference. Choices between the low-risk gamble and the sure thing are easy to discriminate because the standard deviation, $\sigma$, is small; whereas choices between the high-risk gamble and the sure thing are difficult to discriminate because the standard deviation, $\sigma$, is large.

Violations of the independence principle have also been found when choice sets contain more than two options. A famous example originally described by Gerard Debreu (1960) illustrates this case. Envisage a music lover who makes choices between classic recordings. When presented with a choice between a recording of Beethoven's Eighth Symphony (option $B$ ) and a recording of the Debussy quartet (option $D$ ), the music enthusiast has a higher probability of choosing $B$. Then a different recording of Beethoven's Eighth Symphony by the same orchestra, but with a different conductor is added to the choice set (option $B^{\prime}$ ). When evaluating all three options, the music enthusiast has the highest probability of choosing the recording of the Debussy quartet. The probability of choosing a recording of the Eighth Symphony is now divided between the two recordings of the Eighth Symphony, and thus is smaller.
This preference pattern violates fixed utility theories for the following reason: The initial binary choice between Beethoven and Debussy implies that $F[u(B), u(D)]>.50$ and, thus, $u(B)>u(D)$. The advantage of Beethoven over Debussy should continue in the presence of a second Beethoven recording. That is, with three options, $p\left(B \mid\left\{B, D, B^{\prime}\right\}\right)=F\left[u(B), u(D), u\left(B^{\prime}\right)\right]>F[u(D)$, $\left.u(B), u\left(B^{\prime}\right)\right]=p\left(D \mid\left\{B, D, B^{\prime}\right\}\right)$ because $F$ is an increasing function of the first argument and a decreasing function of the remaining arguments. But that is not what happens. Tversky (1972b) called this violation of the independence principle the similarity effect.

Debreu's example has been frequently referred to and adapted to many applications in economics. For instance, the "red-bus blue-bus problem" represents a famous adaptation to research on transportation and travel behavior (e.g., Train 2003). Here a traveler has the choice between a car and a blue bus for traveling to work. Now a second bus, which only differs from the blue bus in its red color, is added to the option set. When now choosing among the three options, decisionmakers might split their preferences for buses between the red bus and the blue bus, violating the IIA principle.

The most common random utility theory, the multinomial logit model described above, can not account for these violations because it assumes that the errors are statistically independent. The joint distribution of utilities for the set of options $Y$ is assumed to be identically and statistically independent for all choice sets. Since these independence violations seem intuitively reasonable, the insufficiency of the multinomial logit model to explain them has initiated an extensive development of new versions of random utility theories. These new versions of random utility theories, predominantly proposed by economists, allow correlations in the joint distributions of utilities (for an overview, see Robert J. Meyer and Barbara E. Kahn 1991; McFadden 2001). These theories have been successfully applied to describe choices in a 
variety of domains, including transportation alternatives (David A. Hensher 1986; McFadden 1974), occupations (Peter Schmidt and Robert P. Strauss 1975), or automobiles (Steven T. Berry 1994; Berry, James Levinsohn, and Ariel Pakes 1999). Three important classes of random utility models can be distinguished: generalized extreme value models, multinomial probit or Thurstone models, and mixed logit models (for an overview, see William H. Greene 2000 or Train 2003).

The most prominent model of the generalized extreme value models (McFadden 1978) is the nested logit model, which assumes that the choice set can be partitioned into subsets, called nests. The error components in equation 2 may be correlated within each subset but are uncorrelated across nests. With this assumption, the IIA principle holds for all options within a nest but not for options across nests. These models can explain particular violations of IIA.

The second class of random utility models, multinomial Thurstone or probit models, including Richard D. Bock's and Lyle V. Jones's (1968) Thurstone model, and Jerry A. Hausman's and David Wise's (1978) conditional probit model, can also explain violations of the IIA. For these models, the error components in equation 2 are assumed to be drawn from correlated normal distributions. Dependencies between these distributions capture correlations between the options. These models are less restrictive than the nested logit models and allow the prediction of "any pattern of substitutions among options" (Meyer and Kahn 1991, p. 98).

The third and most recent class of random utility models is the mixed logit models, also called random coefficient models (Berry 1994; Berry, Levinsohn, and Pakes 1995, 1999; Hensher and Greene 2003; David Revelt and Train 1998). Mixed logit models assume that the weights, $\beta$, of the explanatory variables $k$ are random parameters that vary across individuals $q$. According to these models, the utility of an option is:

$$
U_{q}\left(A_{i}\right)=\sum_{k} \beta_{k q} \cdot x_{i k q}+\varepsilon_{i q},
$$

where $x_{i k q}$ are explanatory variables, $\beta_{k q}$ are the weights for each variable that is assumed to be a random variable following a particular form, such as a normal distribution with a particular correlation matrix, $\Sigma$, and $\varepsilon_{i q}$ are error components independently and identically extreme value distributed. On the one hand, the weights are allowed to vary across individuals to capture the heterogeneity of individuals' preferences; on the other hand, the weights are assumed to be stable within an individual to permit correlations between utilities. These correlations can capture similarity effects, and thereby violations of IIA.

To illustrate how the mixed logit model can predict similarity effects, consider the following problem. Suppose two different types of cars share the same share of the automobile market. The first car, $A$, is rather expensive, but very luxurious, whereas the second car, $B$, is cheap, but offers only the standard equipment. Mixed logit models can explain the equal share by assuming that the weights given to price and comfort vary across consumers. Half of the consumers might give a relatively high weight to the price, whereas the other half gives a relative low weight to the price, so that different utilities for the two cars, but similar market shares, result. Now suppose a new car, $C$, enters the market. It is cheap and similar to car $B$. Consumers who place a relatively high weight on price will find this car appealing, whereas the other consumers who preferred car $A$ will not be attracted to the new car. Therefore, the market share of the cheap car $B$ will decrease due to the market entry of the second cheap car $C$, whereas the market share of the expensive car A stays stable, which represents a IIA violation. Thus, heterogeneity across individuals can produce correlations among the cars' utilities. Moreover, the distributions from which the weights are drawn can be correlated, so a variety of similarity effects can be represented. 
To explain specific similarity effects, it can be helpful to represent the mixed logit model in another form that is mathematically equivalent to equation 7 , but decomposes the random weights $\beta_{q k}$ as follows:

$$
U_{q}\left(A_{i}\right)=\sum_{k} \alpha_{k} \cdot x_{i k q}+\sum_{k} \gamma_{k q} \cdot z_{i k q}+\varepsilon_{i q},
$$

where $\alpha_{k}$ are fixed weights, $\gamma_{k q}$ are random weights with a mean of zero, and $x_{i k q}$ and $z_{i k q}$ are explanatory variables. Since the variables $z_{i k q}$ are multiplied by weights with a mean of zero, the sum of the explanatory variables with the random weights, $\gamma_{k q}$, and the error components, $\varepsilon_{i q}$, represent the error component of the utility of option $i$. Notice that, unlike the error components, $\varepsilon_{i q}$, the random weights, $\gamma_{k q}$, can vary across individuals but not across options. Depending on the values of $z_{i k q}$, options' utilities can be correlated. For instance, if an explanatory variable, $z_{i k q}$, is a dummy variable that reflects membership in a nest, the mixed logit model can approximate the predictions of nested logit models. McFadden and Train (2000) have shown that, under quite general assumptions, any random utility model can be approximated by a mixed logit model.

The mixed logit models and the other newer versions of the random utility models are relatively complex when compared to the multinomial logit model, so that computational problems limited their popularity. But now, since it is easier to do parameter estimations, these models are making a comeback. However, the lack of parsimony makes it difficult to interpret the parameters, and the models are rather ad hoc (e.g., membership in different nests for the nested logit models), and therefore, do not shed much light on why the similarity effects occur. If subsets of options for different choices can not be defined a priori, one should not generalize the predictions of the model to new choices. Likewise, when fitting a mixed logit model to data, one can describe different types of similarity effects, but it is often difficult to predict the effects a priori. Thus, these models are less suitable for making predictions about choices if new options are added to the option set (see Meyer and Kahn 1991). In general, the recent random utility theories have been criticized as being "black box" models that do not specify the psychological process of choice (Eliahu Stern and Harry W. Richardson 2005).

Psychologists have addressed similarity effects, such as the violations of the IIA, by developing descriptive theories. Tversky (1972b) proposed a probabilistic choice theory called elimination by aspects (EBA). The theory makes the crucial assumption of attention switching, which means that the decisionmakers' attention randomly switches between the attributes of the available options (i.e., their aspects). For instance, in the "red-bus blue-bus-problem" the decisionmaker might consider convenience and environment friendliness as two relevant attributes, with the car as having the aspect of being convenient and the busses as having the aspect of being environment friendly. When the decisionmaker's attention first focuses on the convenience, the two buses are eliminated from further consideration and the car is chosen. When, however, first giving consideration to the environment friendliness leads to the car being eliminated, afterwards one of the two buses is chosen. In this process the blue bus splits its share with the red bus, so that the chances of selecting one of the two buses are smaller than the chance of choosing the car.

More generally, let $T$ be a three-alternative set, $T=\{A, B, C\}$. Each option has aspects associated with it, some shared and some unique. Figure 2 illustrates a special case. Let $K$ be the sum of the utilities of all of the aspects, unique aspects $u(a), u(b)$ and $u(c)$, and shared aspects $u(a b), u(a c)$ and $u(b c)$. The probability of selecting $A$ from the set, $T$, is:

$$
\begin{gathered}
p(A \mid T)=[u(a)+u(a b) \cdot p(A \mid\{A, B\})+ \\
u(a c) \cdot p(A \mid\{A, C\})] / K
\end{gathered}
$$




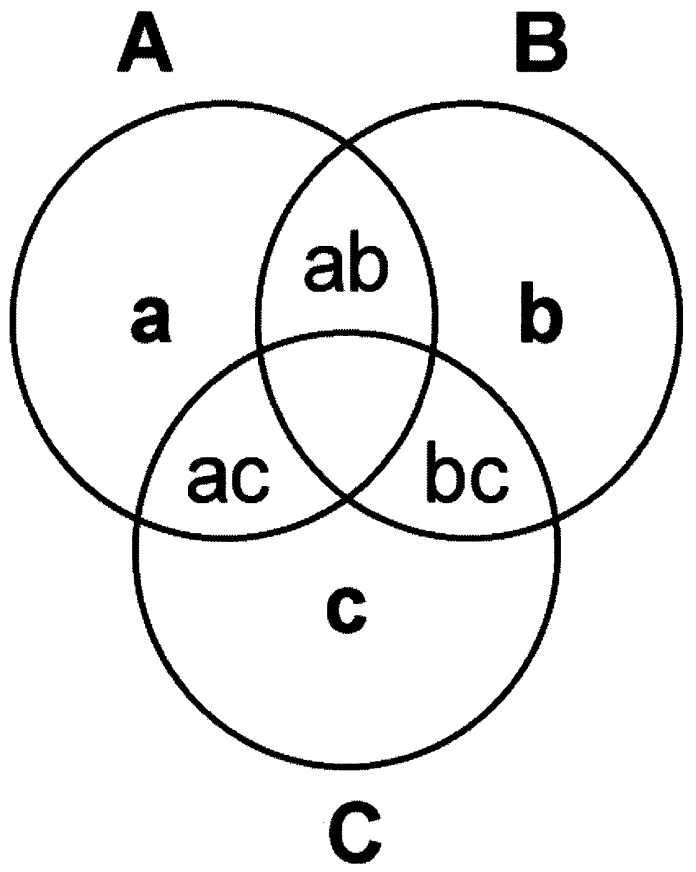

Figure 2. An Alternative Set Where Alternatives Share Aspects

Equation 9 shows the three ways that $A$ could be chosen. First, $a$ could be selected from the set of aspects with probability $u(a) / K$. If so, $A$ would be chosen with probability 1 . Second, $a b$ could be selected with probability $u(a b) / K$, and then $A$ would be chosen over $B$ with probability

$$
\begin{aligned}
p(A \mid\{A, B\})= & (u(a)+u(a c)) /(u(a)+u(a c)+ \\
& u(b)+u(b c)) .
\end{aligned}
$$

Finally, $a c$ could be selected with probability $u(a c) / K$, and $A$ would be chosen over $C$ with probability

$$
\begin{aligned}
p(A \mid\{A, C\})= & (u(a)+u(a b)) /(u(a)+u(a b)+ \\
& u(c)+u(b c)) .
\end{aligned}
$$

The attention switching assumption of the elimination by aspects theory resembles the mechanism the mixed logit model is using to explain IIA violations since both theories assume that the weights of attributes are not fixed. The distinction is that the elimination by aspect theory assumes that weights vary due to attention fluctuations of each individual, whereas the mixed logit model assumes that the weights are fixed for each individual but vary across individuals.

The compromise effect (Itamar Simonson 1989; Tversky and Simonson 1993) is another, more recently observed violation of independence with multiple alternatives. Let $T$ be a three-option set, $T=\{B, C, D\}$ each of which is described by two attributes. Option $B$ has the most advantageous attribute value for one attribute, whereas option $D$ has the most advantageous attribute value for the other attribute. Option $C$ has attribute values that lie between the attribute values of option $B$ and $D$ along both attributes. When presented with only two options, $B$ and $C$, option $B$ is more popular so that $p(B \mid\{B, C\}) \geq$ $p(C \mid\{B, C\})$; however when presented with all three options, the relation between $B$ and $C$ reverses so that $p(C \mid\{B, C, D\})>p(B \mid\{B, C, D\})$, thus violating IIA.

Simonson demonstrated the effect in a study in which participants made choices among cameras. One camera was high in quality and price, and the other was low in quality 
and price. The third option, called the compromise, had moderate values on both dimensions. When individuals were presented with binary choices, participants were roughly indifferent between the two options. However, when given a choice among all three cameras, individuals chose the compromise camera more often than either of the two extremes. This finding violates the independence principle.

To explain the compromise effect, Tversky and Simonson (1993) developed the componential context theory, which requires a dimensional representation of the options in a multidimensional space. In this theory, Tversky and Simonson distinguished between the background context defined by prior choice sets and the local context defined by the immediate choice set. If the background context is held constant, then an option, $A$, is selected from a set, $T$, if it maximizes:

$$
\begin{gathered}
V(A \mid T)= \\
\sum_{k} \beta_{k} v_{k}(A)+\theta \sum_{B \in T} R(A, B)
\end{gathered}
$$

where the overall value of choosing $A$ from set, $T$, depends on the global context and the immediate context. The first term on the right side of the equation reflects the global context and is the sum of the products of each value $v_{k}$ associated with $A$ along each dimension $k$ times the relative contributions of that dimension. The second term that reflects the immediate context is $\theta$, the relative contribution of the immediate context times the sum of the advantages and disadvantages of $A$ relative to other options in the choice set. The relative advantage of $A$ over $B$ on dimension $k$ is defined as:

$$
\begin{gathered}
R(A, B)= \\
\frac{\sum_{k} a d v_{k}(A, B)}{\sum_{k} a d v_{k}(A, B)+\sum_{k} d i s_{k}(A, B)},
\end{gathered}
$$

for which $a d v_{k}(A, B)=v_{k}(A)-v_{k}(B)$ if $v_{k}(A)-$ $v_{k}(B)$ is positive or otherwise zero. If option $A$ has a disadvantage over $B$ on dimension $k$ so that $v_{k}(A)-v_{k}(B)$ is negative, then $\operatorname{dis}_{k}(A, B)=\delta\left[v_{k}(B)-v_{k}(A)\right]$, or otherwise zero. The theory makes the crucial assumption that $\delta$ is a convex function incorporating loss aversion. Due to the loss aversion assumption, the disadvantage of $A$ over $B$ is larger than the corresponding advantage of $B$ over $A$. In the compromise example, the compromise alternative $C$ has small advantages and disadvantages relative to $B$ and $D$, whereas both $B$ and $D$ have relatively large advantages and disadvantages with respect to each other. Due to the convex loss aversion function, the large disadvantages of $B$ and $D$ make them less appealing, whereas due to $C$ 's small disadvantages, it becomes the most attractive alternative.

Interestingly, the elimination by aspects theory (Tversky 1972b) fails to predict compromise effects (see Appendix A for a proof), and the componential context theory fails to explain similarity effects (see Appendix B for a proof). Neither theory provides a general and coherent account of independence violations. Nevertheless, the theories demonstrate that fixed utility theories in which options are evaluated independently of other options are not suitable for explaining the competitive effects of options we reviewed.

Eldar B. Shafir, Daniel N. Osherson, and Edward E. Smith (1993) have argued that, to explain these competitive effects, a comparative approach of decision theories is required. Theories following this comparative approach, like the elimination by aspects theory or the componential context theory, incorporate comparison processes among options in the evaluation process. Shafir, Osherson, and Smith (1993) proposed an advantage model, which also takes into account comparisons among options. However, since the theory is restricted to pairwise choices and is defined as a deterministic theory, it cannot handle the competitive effects of option sets with more than two options or the probabilistic nature of choice.

In sum, two more bounds of rationality have now been crossed. There are numerous 
studies and robust examples of how and when people violate strong stochastic transitivity and the closely related principle of IIA. These consistency principles must be relaxed to account for human choice behavior.

\section{Regularity}

Random utility theories obey a property of choice known as regularity. This principle asserts that the addition of an option to a choice set should never increase the probability of selecting an option from the original set. More formally, assume that $X$ is a complete set of options and $Y$ is a subset of $X(Y \subseteq X)$, that is $Y=\left\{A_{1}, \ldots, A_{m}\right\}$ and $X=\left\{A_{1}, \ldots, A_{n}\right\}$ with $n \geq m$. If $Y$ is presented for choice, and $A_{i}$ is a member of both $Y$ and $X$, then the probability of choosing $A_{i}$ from the set $Y$ is always equal to or greater than the probability of selecting $A_{i}$ from the set $X$, that is, $p\left(A_{i} \mid Y\right) \geq p\left(A_{i} \mid X\right)$. This property holds for random utility theories since it is less likely that $A_{i}$ has the highest utility in a larger set, $X$, with $n$ options than in a smaller set, $Y$, with $m$ options:

$$
\begin{gathered}
p\left(A_{i} \mid Y\right)=p\left(U\left(A_{i}\right)=\max \left\{U\left(A_{1}\right), \ldots, U\left(A_{m}\right)\right\}\right) \\
\geq p\left(U\left(A_{i}\right)=\max \left\{U\left(A_{1}\right), \ldots, U\left(A_{m}\right)\right\}\right) \times \\
p\left(U\left(A_{i}\right)=\max \left\{U\left(A_{1}\right), \ldots, U\left(A_{n}\right)\right\} \mid U\left(A_{i}\right)=\right. \\
\left.\max \left\{U\left(A_{1}\right), \ldots, U\left(A_{m}\right)\right\}\right)=p\left(A_{i} \mid X\right) .
\end{gathered}
$$

That random utility theories obey the regularity principle also holds for newer versions of random utility theories, including the mixed logit model (see Appendix $\mathrm{C}$ for a proof).

Do people obey the principle of regularity? Many studies show robust violations of this principle. The addition of a new option can increase the choice probability for an option in the original set. Such violations are called either asymmetrical dominance effects (Joel Huber, Payne, and Christopher Puto 1982) or attraction effects (Huber and Puto 1983; for an overview, see Timothy B. Heath and Subimal Chatterjee 1995). The difference between these two effects refers to the attribute levels of the new option that is added to the set.

Suppose people are indifferent between two options, $A$ and $B$. The "decoy" option, $D$, is then added to the choice set. $D$ is said to be "asymmetrically dominated" if it has values that are worse than those of another option, such as $B$, along one attribute and its values are no better than those of $B$ on all other attributes. Asymmetric dominance effects occur if the probability of choosing $B$ increases when $D$ is added to the choice set. Attraction effects are similar to asymmetric dominance effects, but $D$ is not asymmetrically dominated by $B$. Instead, $D$ simply seems a lot worse.

These effects are illustrated with the options in table 2. Suppose a decisionmaker is indifferent between two laptop computers, $A$ and $B . A$ is relatively heavy, but has a large display. $B$ is lighter, with a smaller display. Now the decisionmaker considers a third computer, $D$ that is heavier than $B$, but has the same sized display. The mere presence of $D$ makes $B$ seem better. The probability of selecting $B$ from the set of three computers $(A, B$, and $D)$ is greater than the probability of selecting $B$ from the set of two computers $(A$ and $B)$. This increase in probability is the asymmetric dominance effect. Now suppose that the decoy, $D$, is not asymmetrically dominated by $B$, yet it still seems inferior to $B$ (e.g., the display for $D$ is 13.2 inches, rather than 13 inches). Here, the increase in the probability of $B$ with the inclusion of $D$ is called the attraction effect. In both cases, the result is a violation of regularity.

Asymmetrical dominance effects have been found in choices among gambles (Douglas H. Wedell 1991), consumer products and services (Wedell and Jonathan C. Pettibone 1996), job applicants (Scott Highhouse 1996), and political candidates in U.S. elections (Yigang Pan, Sue O'Curry, and Robert Pitts 1995). The effects occur with choices and other measures of preference (Dan Ariely and Thomas S. Wallsten 1995; Sanjay Mishra, U.N. Umesh, and Donald E. 
TABLE 2

Illustration of Asymmetric Dominance Effects with Choices Among Laptops

\begin{tabular}{cccc}
\hline \hline & $A$ & $B$ & $D$ \\
\hline Weight & $6 \mathrm{lbs}$ & $3 \mathrm{lbs}$ & $3.5 \mathrm{lbs}$ \\
Display Size & $15 \mathrm{ins}$ & $13 \mathrm{ins}$ & $13 \mathrm{ins}$ \\
\hline
\end{tabular}

Stem 1993; Pan and Donald R. Lehmann 1993; Tversky and Simonson 1993). Finally, the effects are highly robust in both withinsubject designs (repeated choices by the same individuals) and between-subject designs (different choices across groups of individuals).

Random utility theories cannot account for violations of regularity because the joint distribution of utilities for the option set, $Y$, is assumed to remain the same when options are added to create a larger set, $X$. However, the empirical evidence suggests that the joint distribution of utilities for the larger set changes depending on the options that are included in the set. A psychological theory that specifies the cognitive process of choice and can explain dependencies among options has been proposed by Busemeyer and Townsend (1993) and Robert M. Roe, Busemeyer, and Townsend (2001). It is called decision field theory. According to this theory, choices are the result of a dynamic process during which the decisionmaker retrieves, compares, and integrates random utilities over time. During the deliberation period, a random utility is retrieved for each option, $A_{i}$, at each moment in time $t$, denoted $U_{t}\left(A_{i}\right)$. These utilities are integrated across time by a linear dynamic process to form a preference state:

$$
\begin{gathered}
P_{t}\left(A_{i}\right)=s \cdot P_{t-1}\left(A_{i}\right)+U_{t}\left(A_{i}\right)- \\
\sum_{j=1} c_{i j} \cdot P_{t-1}\left(A_{j}\right), j \neq i,
\end{gathered}
$$

where $s$ is a weight that reflects the memory of recent preferences. The coefficients, $c_{i j}=c_{j i}$, are a function of the distances between the options in a multidimensional attribute space.
The theory postulates that the decisionmaker forms preference states for options that are the result of previous preference states plus the currently retrieved utilities for options minus negative influences of alternative options in the choice set. If a preference state for an option crosses a threshold, the decisionmaker selects that option. During the dynamic process of comparing the alternatives, attention switches from one attribute to another; thus, the theory also includes an attention switching assumption as was proposed by the elimination by aspect theory (Tversky 1972b), which allows the explanation of similarity effects. In addition, the theory assumes that options compete with each other (in the case where $\left.c_{i j}>0\right)$ and similar options compete more heavily than dissimilar options by exerting stronger negative influences. These competitive effects can predict violations of regularity (see Roe, Busemeyer, and Townsend 2001; Busemeyer and Adele Diederich 2002). The theory also predicts that these violations of regularity should increase when decisionmakers deliberate longer, a prediction that has been supported in several experiments (Simonson 1989; Wedell 1991; Ravi Dhar, Stephen M. Nowlis, and Steven J. Sherman 2000).

Another psychological theory that can explain dependencies between options is a nonlinear adaptive network model called the leaky, competing accumulator model (Marius Usher and James L. McClelland 2004). This theory is very similar to decision field theory in the sense that it also assumes that preferences develop in a dynamic manner over time. Likewise, it includes the attention 
TABLE 3

Gambles Used by Tversky (1969) to Demonstrate Intransitive Preferences

\begin{tabular}{lccccc}
\hline \hline & $A$ & $B$ & $C$ & $D$ & $E$ \\
\hline Probability of Winning & $7 / 24$ & $8 / 24$ & $9 / 24$ & $10 / 24$ & $11 / 24$ \\
Payoff & $\$ 5.00$ & $\$ 4.75$ & $\$ 4.50$ & $\$ 4.25$ & $\$ 4.00$ \\
\hline
\end{tabular}

switching assumption to explain similarity effects. In contrast to decision field theory, it assumes loss aversion to explain regularity violations. Thus, it combines the attention switching assumption of the elimination by aspect theory (Tversky 1972b) with the loss aversion assumption of the componential context theory (Tversky and Simonson 1993) to explain IIA and regularity violations.

\section{Weak Stochastic Transitivity}

Weak stochastic transitivity is perhaps the weakest bound on rationality of the five principles that we consider. This principle states that for any arbitrary triple of options, $A, B$, and $C$ :

$$
\begin{gathered}
\text { If } p(A \mid\{A, B\}) \geq .50 \text { and } p(B \mid\{B, C\}) \geq .50, \\
\text { then } p(A \mid\{A, C\}) \geq .50 .
\end{gathered}
$$

Weak stochastic transitivity lies at the heart of weak probabilistic choice theories. Those theories based on standard utility assumptions must satisfy the principle because $u(A) \geq u(B) \geq u(C) \rightarrow p(A \mid\{A, C\})$ $\geq .50$. Furthermore, many strong probabilistic choice theories must also satisfy weak stochastic transitivity, including all simple scalable or fixed utility theories, elimination by aspects theory, and decision field theory. The contrast-weighting model and the stochastic-difference model can, however, account for violations of weak stochastic transitivity. Among the random utility models considered here, only the mixed logit model allows violations of weak stochastic transitivity (for an example, see Appendix D). In contrast, the other random utility models, like, for instance, the generalized extreme value model, obey the principle of weak stochastic transitivity (see Appendix E for a proof).

It is interesting to look closely at a classic study by Tversky (1969) to understand the conditions under which violations of weak stochastic transitivity can occur. Tversky asked participants to choose between pairs of gambles, as shown in table 3. Gambles varied in probabilities and payoffs, but expected values were similar. When presented with gambles having similar probabilities, some participants frequently preferred the gamble with the larger payoff. That is, they preferred $A$ to $B, B$ to $C, C$ to $D$, and $D$ to $E$. But when presented with gambles that substantially differed in probabilities, they preferred the gamble with the greater probability of winning. That is, they preferred $E$ to $A$. Tversky's results were later replicated by Harold R. Lindman and James Lyons (1978) and extended by Jonathan W. Leland (1994).

Tversky (1969) proposed an additive difference model based on the concept of a just noticeable difference (Luce 1956, p. 180) to account for the violations. A just noticeable difference is the amount of change required in a physical stimulus before people detect a difference between similar stimuli on some percentage of occasions. Tversky argued that differences in probabilities for the adjacent gambles (i.e., $A$ and $B$, or $B$ and $C$ ) were less than a just noticeable difference, or not sufficiently great for people to differentiate between gambles. The additive difference model is a noncompensatory, lexicographic semi-order. A model is noncompensatory if the information from one dimension cannot be compensated by any combination of information from other less important dimensions 
(see also Rieskamp and Ulrich Hoffrage 1999). In this account, decisionmakers select the gamble with the highest value on the most important dimension, but if the difference between gambles on that dimension is too small to be detected, decisionmakers consider the next most important dimension and choose the gamble with the highest value on that dimension, and so on.

Ariel Rubinstein (1988) and Leland (1994) offer a similar account to describe choices between gambles. They argue that people follow a sequential decision process in which they first check whether one gamble dominates the other. Then they compare the probabilities across gambles and outcomes across gambles. If levels of either attribute are perceived as being similar on one dimension and dissimilar on the other dimension, the dissimilar dimension becomes decisive. Only after these steps are completed do decisionmakers move to an unspecified third step of selecting a gamble. This account, also based on perceived similarity, predicts the intransitive choices described above. The contrast-weighting model offered by Mellers and Biagini (1994) is a more precise version of this idea in which the effects of similarity and dissimilarity are reflected in the weights associated with the contrasts.

The idea of a noncompensatory decision process that focuses on one dimension at a time combined with a just noticeable difference is a reasonable explanation for such violations, especially when options differ along many dimensions and the differences vary substantially. It is efficient to place greater attention on dimensions with larger differences and ignore or discount dimensions with smaller differences (Mellers and Biagini 1994). Furthermore, theories that permit violations of weak stochastic transitivity (Tversky 1969; Mellers and Biagini 1994; GonzalezVallejo 2002) assume that decisionmakers compare options intradimensional-wise, that is, focusing on each dimension sequentially. Intradimensional comparisons are usually easier than interdimensional comparisons, especially when dimensions differ in measurement units (Tversky 1969). Finally, intradimensional comparisons simplify the detection of dominance relationships.

Another class of theories that allow intransitive choices is regret theories (David E. Bell 1982; Peter C. Fishburn 1982; Loomes and Sugden 1982). These theories assume that the decisionmaker prefers the option with the highest utility but the utility of an option depends on an independent evaluation of the option and a comparative evaluation with the other option as follows:

$$
\begin{gathered}
u\left(A_{i}\right)=\sum_{s} p_{s} \cdot\left[u\left(x_{s i}\right)+\right. \\
\left.w \cdot R\left(u\left(x_{s i}\right), u\left(x_{s j}\right)\right)\right],
\end{gathered}
$$

where $A_{i}$ is the option under consideration, $A_{j}$ is the alternative option, $s$ refers to states with consequences $x$, and where $w=1$ if $u\left(x_{s i}\right)>u\left(x_{s j}\right)$, and $w=-1$ otherwise. The nonlinear function $R\left(u\left(x_{s i}\right), u\left(x_{s j}\right)\right)$ is increasing in its first argument and decreasing in its second argument; a possible function could be $R\left[u\left(x_{s i}\right), u\left(x_{s j}\right)\right]=\left[u\left(x_{s i}\right)-u\left(x_{s j}\right)\right]^{2}$.

To illustrate, consider three pairwise choices between the gambles $A, B$, and $C$, with outcomes determined by throwing a die. Gamble $A$ has the smallest payoff of $\$ 2$ with certainty, gamble $B$ has a medium payoff of $\$ 3$ if the die throw results in a one, two, three, or four, and option $C$ has the highest payoff of $\$ 5$ if the die throw results in a five or six. In a choice between $A$ and $B$, $A$ has the higher utility because the anticipated regret associated with $B$ if the die comes up five or six is disproportionately large relative to the regret associated with $A$ if a one, two, three, or four were thrown. Furthermore, the decisionmaker will prefer $B$ to $C$ using the same logic. However, in a choice between $A$ and $C$, the decisionmaker will prefer $C$, because the anticipated regret with $A$ if a one or two is thrown is extremely high. As this examples shows, regret theories can explain intransitive choices, but they cannot explain compromise or attraction effects, nor can they handle the probabilistic nature of choice. 
How common are violations of weak stochastic transitivity? John M. Davis (1958) found some violations but decided they were nonsystematic. Donald Davidson and Marschak (1959) studied preferences for bets and found that 7 percent to 14 percent of choice triples violated transitivity. Kenneth R. MacCrimmon (1968) examined the choices of thirty-eight business managers and found that eight exhibited some intransitivities, although the violations did not appear to be reliable. William $\mathrm{T}$. Harbaugh, Kate Krause, and Timothy R. Berry (2001) examined transitivity in children and found relatively few violations, although many inconsistencies. The intransitivities found by Tversky (1969) were based on a preselected group of participants for whom inconsistent behavior had been observed before. In a recent summary of the literature, Luce (2000) pointed out that intransitivities may occur, but it may be due to the simple fact that choices are not always consistent (see also Jean Claude Falmagne and Geoffrey Iverson 1979).

Other researchers have found systematic violations of weak stochastic transitivity (Henry Montgomery 1977; Robert H. Ranyard 1977; David V. Budescu and Wendy Weiss 1987; Birnbaum, Jamie N. Patton, and Melissa K. Lott 1999; Lindman and Lyons 1978; Peter Roelofsma and Daniel Read 2000). However, these violations-in stark contrast to violations of strong stochastic transitivity-are relatively rare. That is, there are reliable circumstances where they occur, but those circumstances are fairly unusual (see Becker, Degroot, and Marschak 1963; Krantz 1967; Rumelhart and Greeno 1971; Sjoberg 1975, 1977; Sjoberg and Capozza 1975; Mellers, Chang, Birnbaum, and Ordonez 1992). For these reasons, it can be argued that the principle of weak stochastic transitivity should generally be retained as a bound of rationality. Descriptive theories that do not allow violations of weak stochastic transitivity usually perform reasonably well when predicting choice behavior in many, perhaps even most, situations.

\section{Discussion}

The goal of the present review is to examine how, when, and why people violate consistency principles that embody the traditional view of rationality. Five constraints on preferential choice were addressed. Those constraints, or consistency principles, are partially ordered on a continuum from strictest to weakest. Figure 1 shows that the principles include perfect consistency, strong stochastic transitivity, IIA, regularity, and, finally, weak stochastic transitivity. The evidence for and against each principle was examined. The empirical effects, their connections to principles, and brief definitions of the effects are presented in table 4 . The frequency and breadth of the violations declined as we proceeded from stricter to weaker bounds. There was strong evidence against perfect consistency, strong stochastic transitivity, independence, and regularity. This evidence is important because it implies that descriptive theories must relax these constraints in order to make accurate predictions.

\subsection{Comparison of Models}

Deterministic theories of choice, such as the subjective expected utility theory (Leonard J. Savage 1954) or multiattribute utility theory (Keeney and Raiffa 1976), cannot accommodate the fact that choices are probabilistic. The "conventional strategy" (Starmer 2000) for handling this problem is to claim that inconsistencies are random. Though tempting, this strategy fails to explain how and when choice probabilities will vary across sets. To accomplish the latter, two classes of probabilistic choice theories were proposed: fixed utility theories (e.g., Debreu 1958; Luce 1958) and random utility theories (e.g., Thurstone 1959; Becker, Degroot, and Marschak 1963; McFadden 2000). 
TABLE 4

SUMMARY OF EFFECTS

\begin{tabular}{|c|c|c|}
\hline Principles & Emperical Evidence & Brief Description of Effects \\
\hline $\begin{array}{l}\text { Strong Stochastic } \\
\text { Transitivity }\end{array}$ & Comparability Effects & $\begin{array}{l}p(A \mid\{A, B\})>.5, p(B \mid\{B, C\})>.5 \text {, and } p(A \mid\{A, C\})>.5 \\
\text { but } p(B \mid\{B, C\})>p(A \mid\{A, C\}) \text { when } B \text { and } C \text { have similar values on one dimension }\end{array}$ \\
\hline \multirow{2}{*}{$\begin{array}{l}\text { Independence } \\
\text { from Irrelevant } \\
\text { Alternatives }\end{array}$} & Similarity Effects & $\begin{array}{l}p\left(B_{1} \mid\left\{B_{1}, D\right\}\right)>p\left(D \mid\left\{B_{1}, D\right\}\right) \\
\text { but } p\left(B_{1} \mid\left\{B_{1}, D, B_{2}\right\}\right)<p\left(D \mid\left\{B_{1}, D, B_{2}\right\}\right)\end{array}$ \\
\hline & Compromise Effects & $\begin{array}{l}p(B \mid\{B, C\})>p(C \mid\{B, C\}) \text { but } p(C \mid\{A, B, C\})>p(B \mid\{A, B, C\}) \text { when values of } C \\
\text { are between values of } A \text { and } B \text { on all dimensions }\end{array}$ \\
\hline \multirow[t]{2}{*}{ Regularity } & $\begin{array}{l}\text { Asymmetric Dominance } \\
\text { Effects }\end{array}$ & $p(A \mid\{A, B, D\})>p(A \mid\{A, B\})$ when $D$ is dominated by $A$, but not by $B$ \\
\hline & Attraction Effects & $p(A \mid\{A, B, D\})>p(A \mid\{A, B\})$ when $D$ is much inferior to $A$, but not to $B$ \\
\hline $\begin{array}{l}\text { Weak Stochastic } \\
\text { Transitivity }\end{array}$ & Transitivity Violations & $p(A \mid\{A, B\})>.5, p(B \mid\{B, C\})>.5$, but $p(C \mid\{A, C\})>.5$ \\
\hline
\end{tabular}

Fixed utility theories that assume a welldefined preference function imply strong stochastic transitivity and the IIA. Again, there is a considerable body of empirical evidence, including similarity effects, comparability effects, and the compromise effect, showing violations of these principles. Random utility theories imply a consistency principle of regularity. There is a substantial body of evidence, including attraction effects and asymmetric dominance effects, against regularity.

A number of psychological theories have been proposed to accommodate the violations. Table 5 summarizes many of the theories previously mentioned and shows which effects they can and cannot predict. Tversky's (1972b) elimination by aspects theory provides an elegant account of similarity effects (violation of independence) but fails to account for asymmetric dominance effects and attraction effects (violations of regularity). Tversky and Simonson (1993) developed the componential context theory to account for compromise effects but their theory cannot describe similarity effects. Violations of strong and weak stochastic transitivity can be explained by the contrast-weighting model (Mellers and Biagini 1994) and the stochastic difference model (Gonzalez-Vallejo 2002). But since these models have only been defined for binary choices, they cannot predict asymmetric dominance effects, attraction effects, compromise effects, or similarity effects. The most general theories considered, decision field theory (Busemeyer and Townsend 1993; Roe, Busemeyer, and Townsend 2001) and the leaky, competing accumulator model (Usher and McClelland 2004), can explain most effects, except violations of weak stochastic transitivity.

In sum, we have reviewed several theories that can predict, to differing degrees, violations of the consistency principles. We now face the more general question of how to select a descriptive theory of preferential choice. Most theorists agree that two criteria are essential for model selection: predictability and parsimony (see Heinz Linhart and Walter Zucchini 1986; Pitt, Myung, and Zhang 2002). The best theory is one that accurately predicts human behavior and is simple. Unfortunately, when fitting a model to the data, accuracy and parsimony usually 
TABLE 5

Summary of Principles, Violations, and Theoretical ACCOUnts

\begin{tabular}{|c|c|c|c|c|c|c|c|c|c|c|c|}
\hline \multirow{2}{*}{$\begin{array}{l}\text { Principles } \\
\text { Consistency }\end{array}$} & \multirow{2}{*}{\begin{tabular}{l}
\multicolumn{1}{c}{ Violations } \\
Variations in \\
Choices
\end{tabular}} & \multicolumn{8}{|c|}{ Theoretical Accounts } & & \\
\hline & & MNL & GEV & MLM & DFT & LCA & CWM & SDM & EBA & & \\
\hline $\begin{array}{l}\text { Strong } \\
\text { Stochastic } \\
\text { Transitivity }\end{array}$ & $\begin{array}{l}\text { Comparability } \\
\text { Effects }\end{array}$ & & GEV & MLM & DFT & LCA & CWM & SDM & EBA & & $\mathrm{ADM}$ \\
\hline $\begin{array}{l}\text { Independence } \\
\text { from Irrelevant }\end{array}$ & Similarity Effects & & GEV & MLM & DFT & LCA & & & EBA & & \\
\hline Alternatives & $\begin{array}{l}\text { Compromise } \\
\text { Effects }\end{array}$ & & GEV & MLM & DFT & LCA & & & & CCT & \\
\hline Regularity & $\begin{array}{l}\text { Asymmetric } \\
\text { Dominance } \\
\text { Effects }\end{array}$ & & & & DFT & LCA & & & & CCT & \\
\hline & Attraction Effects & & & & DFT & LCA & & & & CCT & \\
\hline $\begin{array}{l}\text { Weak } \\
\text { Stochastic } \\
\text { Transitivity }\end{array}$ & $\begin{array}{l}\text { Transitivity } \\
\text { Violations }\end{array}$ & & & MLM & & & CWM & SDM & & & $\mathrm{ADM}$ \\
\hline
\end{tabular}

where MNL = Multinomial Logit Model, GEV = Generalized Extreme Value Model, MLM = Mixed Logit Model, DFT = Decision Field Theory, LCA = Leaky, Competing Accumulator Model, CWM = Contrast-Weighting Model, SDM = Stochastic Difference Model, EBA = Elimination by Aspects, $\mathrm{CCT}=$ Componential Context Theory, and ADM = Additive Difference Model

work in opposition; the more complex the model, the better the fit.

For choice contexts with equally similar or equally discriminable options, violations of IIA are less common and simple scalable models should suffice. However, this case is fairly unusual and fails to hold in most consumer choice tasks (e.g., whenever there are correlated attribute values or unequal variances in payoffs). If options do vary in similarity or discriminability but all of the obviously deficient options have been removed, regularity is likely to be satisfied although IIA could be violated. In this situation, recent random utility models like the mixed logit model can be effective. Thus, it can happen that multiple theories can predict the same violations. For example, both mixed logit models and decision field theory are capable of explaining similarity effects. However, the mixed logit model requires different parameters, whereas decision field theory can explain these results using the same set of parameters. In this instance, decision field theory provides a simpler and more parsimonious explanation. Moreover, unlike decision field theory and the leaky, competing accumulator model, mixed logit models are unable to explain violations of the regularity principle. There are many consumer choice situations that contain deficient options (e.g., a product that is extremely overpriced because of its brand name), and violations of regularity would be expected. When this occurs, one needs to turn to more complex models that do not require regularity. In sum, only the more complex models such as the decision field theory, the leaky competing accumulator model, or the mixed logit model can explain several of the behavior effects that we have reviewed. Future work will need to focus on direct 
comparisons of these models to explore how appropriately the models predict human behavior.

Another important principle to consider for model selection is generalizability. The goal of model selection is to find a theory that is capable of predicting not only the observed choices in an experiment but also other behaviors that are independent of the particular experiment used for parameter estimation. When predicting new data, simpler models are often more robust and achieve higher levels of accuracy under new conditions. This may be particularly important for the design of new products. Simpler models, built on psychological principles rather than ad hoc parameters, promise to be more effective for purposes of generalization. For example, Tversky's (1972b) elimination by aspects model provides mechanisms to make a priori predictions about the effects of new options.

Is there a proper balance between predictability and complexity? The answer depends on the application and the circumstances. Descriptive theories should be able to predict violations of consistency principles when violations are commonplace. A review of the literature suggests that violations are frequent for all of the principles that we examined, except perhaps weak stochastic transitivity. These violations are quite systematic, but relatively rare (cf. Mellers and Biagini 1994). In fact, William H. Morrison (1963) noted that the theoretical number of intransitive triples in a complete set of pairwise comparisons is quite limited: Given $n$ options, the maximum number of intransitive triples is $(n+1) /(4(n-2))$. As $n$ increases, the maximum number of intransitive triples approaches one fourth. This result implies that even if a decision process produces a maximum of intransitive choices, the intransitive triples will still be relatively atypical. Therefore, increasing the complexity of a theory to account for violations of weak stochastic transitivity appears less justified.

\subsection{When Are Violations of Consistency Principles Reasonable?}

We have argued that some violations of consistency principles are common. Now we address the question of whether these violations are reasonable. Rationality is traditionally defined as compliance with consistency principles, and inconsistency implies "irrationality" (Shafir and Robin A. LeBoeuf 2002). This approach has been widely challenged (e.g., Aumann 1962; Machina 1982; Cohen and Jaffray 1988; Gigerenzer 1991, 1996a, 1996b; Lopes and Oden 1991; Hammond 1996; Lopes 1996; McFadden 1999; Mongin 2000). Selten (2001, p. 15) argued that "behavior should not be called irrational simply because it fails to conform to norms of full rationality" and that "bounded rationality is not irrationality." Bounded rationality is a more accurate description of human behavior taking into account that people make decisions with limited time, knowledge, and computational power. This view, initially proposed by Simon (1956, 1983), recognizes that the lack of compliance with consistency principles could, in fact, be functional. For example, the benefit of a quick decision could easily outweigh the cost of some inconsistency.

How reasonable are violations of the five consistency principles discussed here? We will begin with perfect consistency, a principle that follows from deterministic choice theories. If individuals had "true" preferences, they might find themselves at a distinct disadvantage if they deviated from those preferences, especially in the long run. However, in dynamic environments, where individuals are continually faced with new sets of options, some degree of variability is beneficial for exploring the environment. A competitive environment is another case where some degree of variability could be desirable. The decisionmaker whose choices are difficult to forecast has an advantage over a predictable opponent. In fact, in zero-sum games stochastic decisions, representing 
mixed strategies, are the only existing Nash equilibrium defining optimal behavior. In sum, these real-world advantages of variable preferences could easily carry over into artificial stable laboratory settings.

Numerous studies cast doubt on the idea that people possess "true" preferences in the sense of fixed utility theories. Instead, the evidence suggests that people construct or discover their preferences when presented with option sets. The unfolding of these processes depends on the circumstances of the choice situation (i.e., the time pressure, the stakes, and the way in which preferences are elicited) and on the options under consideration (i.e., the context and the frame). The attributes an individual uses for comparing options might depend on the option set. Their relative "importance" could depend on the similarity of attribute values, and thus explain comparability effects. Focusing the individual's attention on attributes with different values seems like an efficient and reasonable form of decision making.

Violations of IIA could also be reasonable. For instance, Greene (2000, p. 864) in his standard textbook in econometrics writes that the principle "is not a particularly appealing restriction to place on consumer behavior." David Brownstone and Train (1999, p. 110) argue that the substitutions effects that are implied by the IIA principle "can be unrealistic in many settings" and McFadden (2001, p. 358) argues that they "may not be behaviorally plausible." Likewise, Hensher and Greene (2003, p. 135) regard the principle as "questionable."

The famous "red-bus blue-bus" example described above shows that in many situations it appears unreasonable to follow the IIA principle. Amartya Sen (1993) presented another illustrative example of a decision as to whether to take an apple out of a fruit basket at a dinner party. A person who behaves decently might not take the apple if it is the last. But, if more than one apple is left in the basket, the same person might take an apple. Of course, the additional apples are not really "independent" because they change the consequences of the original option (i.e., norms of politeness). However, this is exactly why violations of independence occur: When people construct their preferences in a choice situation, additional options can change the consequences of other options or the perception of these consequences.

A decision process that constructs or discovers preferences could also explain violations of regularity. The addition of new options to a choice set (i.e., adding a less attractive option) systematically influences preferences for options in the original set, violating the regularity principle. These types of contextual effects need not be unreasonable. When evaluating choice sets, such as those in table 2, participants in an experiment might infer that a dominated option, such as $D$, was included in the choice set to provide useful information (Paul H. Grice 1975, 1989; see also Denis J. Hilton 1995). Participants might infer that laptop computers with large displays, such as $A$, are relatively uncommon and perhaps less desirable than laptop computers with smaller displays, such as $B$ and $D$. If the market for larger displays is small, $B$ could be the best choice.

Birger Wernerfelt (1995) made a similar argument by suggesting that people use the available options to draw inferences about their own tastes and utilities. Decisionmakers who know their relative but not their absolute utilities could make assumptions about the correct choice from the choice set if they believed the options reflected population utilities. They would use the market offerings to assign utilities and infer their own preferences. Drazen Prelec, Wernerfelt, and Florian Zettelmeyer (1997) developed a context model that reflects simple inferences about one's own preferences (ideal points) given what is available (product "addresses"). They generate predictions that can simulate compromise and attraction effects. Though promising, their model requires additional information (category ratings) that reflect a decisionmaker's ideal 
point and his or her perceptions of product addresses.

In sum, the different violations of consistency principles can be justifiable within a "bounded rationality" framework. Bounded rationality stresses how choices depend on the characteristics of the environment. It also stresses how the selection of simple strategies can be quite adaptive. For example, Gigerenzer and Daniel G. Goldstein (1996) demonstrated that a simple lexicographic heuristic provided accurate predictions in a paired-comparison inference task. If a heuristic is fairly good, it might be beneficial, even if it occasionally produces intransitive choices. Consistent, Rieskamp and Otto (2006) could show that simple heuristics can predict individuals' choices quite well. Warren Thorngate (1980) and Payne, Bettman, and Johnson (1988) demonstrated that simple heuristics can also be efficient when choosing among options with a flat maximum. Another heuristic that can lead to intransitivities is the majority rule (e.g., Kenneth O. May 1954; Maya Bar-Hillel and Avishai Margalit 1988). With this rule, the decisionmaker simply counts the number of dimensions where an option has an advantage (disregarding the magnitude of the advantages) and selects the option with the greatest number of advantages. By focusing only on the relative advantage of an option compared to alternative options, the majority rule can violate transitivity. Nonetheless, these heuristics, such as the lexicographic or majority rule, require only a small subset of the available information, which is then easy to process. Heuristics can be regarded as "approximation methods" of more complex strategies, and by "using such methods ... we implicitly assume that the world is not designed to take advantage of our approximation methods," whereas experiments are often "designed with exactly that goal in mind" (Tversky 1969, p. 46).

The traditional argument that transitivity is a cornerstone of rationality is based on the observation that a decisionmaker who violates the axiom may be "taken" by a money pump (see Davidson, John Charles C. McKinsey, and Suppes 1955; Robin P. Cubitt and Sugden 2001). Being "taken" means that a decisionmaker who starts with an option and cycles through a series of choices, paying each time for a new option, will eventually end up with less money and the original option. It is unquestionable that such intransitive choices are costly and unreasonable. However, we do not encounter money pumps very often and, if we did, we would probably learn to avoid them. As experimental results show (YunPeng Chu and Ruey-Ling Chu 1990), building a money pump is not easy because people typically recognize their intransitive choices and quickly change their behavior. Thus, money pump "arguments are logical bogeymen" (Lopes 1996, p. 187) that demonstrate how irrational behavior in principle could occur, but that do not show that irrational behavior in fact occurs.

The regular, systematic, and robust violations of consistency set the requirements for descriptive theories of choice. The violations we have discussed are interrelated in subtle and interesting ways; they illustrate systematic behavioral principles. Whether they represent rational or irrational behavior might be analogous to asking whether the glass is half empty or half full. What really matters is (1) understanding how and why people make choices and (2) being able to predict those choices. Debates about rationality focus attention far too narrowly. A broader conversation-one that considers reasonable behavior, adaptive behavior, and the environment in which choices occur-is long overdue. We look forward to this shift in focus and the related evidence and theories that will unfold in the next several decades.

\section{APPENDICES}

Appendix A: Proof that the elimination by aspect theory cannot explain compromise effects. 
Consider a choice set consisting of three cameras labeled $A, B$, and $C$. $A$ is a highquality camera with many high-quality features and is very expensive; $B$ is a low-quality camera with no high-quality features and is quite cheap; $C$ is between the two extremes, having some, but not all, of the high-quality features and is moderately priced. The compromise camera shares some features with both extreme options. With the compromise effect, $p(A \mid\{A, B\})=p(A \mid\{A, C\})=p(B \mid\{B, C\})$. But, when the three options are evaluated together, $p(C \mid\{A, B, C\})>p(A \mid\{A, B, C\})$ and $p(C \mid\{A, B, C\})>p(B \mid\{A, B, C\})$. The componential context theory (Tversky and Simonson 1993) predicts the compromise effect. In contrast, the elimination by aspects theory (Tversky 1972b) cannot predict the effect, as shown below. In the elimination by aspects theory, alternatives are composed of common and unique positive aspects:

$$
\begin{aligned}
a= & \text { unique aspects of } A, \\
b= & \text { unique aspects of } B, \\
c= & \text { unique aspects of } C, \\
a b= & \text { common aspects between } A \text { and } B, \\
& \text { but not with } C, \\
a c= & \text { common aspects between } A \text { and } C, \\
& \text { but not with } B, \text { and } \\
b c= & \text { common aspects between } B \text { and } C, \\
& \text { but not with } A .
\end{aligned}
$$

Let $u$ be a scale that assigns a positive value to these aspects so that, for instance, $u(a)$ represents the positive value of aspects $a$ to the decisionmaker. Cameras $A$ and $C$ share some high-quality features, whereas cameras $A$ and $B$ have little in common so that $u(a c)>u(a b)$. Cameras $B$ and $C$ share the positive aspect of not being very expensive, which cameras $A$ and $C$ do not share so that $u(b c)>u(a b)$. Thus, on the basis of the similarity relations among the choice options, it can be assumed that:

$$
u(a c)>u(a b) \text { and } u(b c)>u(a b) .
$$

These assumptions, regarding the mapping from options to similarity relations, are essential for EBA to account for the similarity effect (see Tversky 1972b). For binary choices, EBA predicts:

$$
\begin{gathered}
p(A \mid\{A, B\})= \\
\frac{u(a)+u(a c)}{u(a)+u(a c)+u(b)+u(b c)} .
\end{gathered}
$$

The compromise effect implies that the choice probabilities for the three binary choices are equal so that:

$$
\begin{gathered}
u(a)+u(a c)=u(b)+u(b c), \\
u(a)+u(a b)=u(c)+u(b c), \text { and } \\
u(b)+u(a b)=u(c)+u(a c) .
\end{gathered}
$$

From (A1) and (A5) it is known that $u(b)>u(c)$ and from (A1) and (A4) it is known that $u(a)>u(c)$. For triadic choices, EBA predicts

$$
\begin{gathered}
p(A \mid\{A, B, C\})=[u(a)+u(a b) \cdot p(A \mid\{A, B\})+ \\
u(a c) \cdot p(A \mid\{A, C\})] / u(K),
\end{gathered}
$$

where $u(K)=[u(a)+u(b)+u(c)+u(a b)+$ $u(a c)+u(b c)]$. The compromise effect implies

$$
\begin{gathered}
p(C \mid\{A, B, C\})>p(A \mid\{A, B, C\}) \text { or } \\
{[u(c)+.5(u(a c)+u(b c))] / u(K)>} \\
{[u(a)+.5(u(a b)+u(a c))] / u(K),} \\
p(C \mid\{A, B, C\})>p(B \mid\{A, B, C\}) \text { or } \\
{[u(c)+.5(u(a c)+u(b c))] / u(K)>} \\
{[u(b)+.5(u(a b)+u(b c)\}] / u(K) .}
\end{gathered}
$$

If both sides of the inequalities are multiplied by 2 and $u(K)$ is cancelled out, the result is:

$$
\begin{gathered}
{[u(c)+u(b c)+u(c)+u(a c)]>} \\
{[u(a)+u(a c)+u(a)+u(a b)],} \\
{[u(c)+u(b c)+u(c)+u(a c)]>} \\
{[u(b)+u(b c)+u(b)+u(a b)] .}
\end{gathered}
$$

With the substitutions from (A3) and (A4), inequality (A7) can be rewritten as

$$
\begin{gathered}
{[u(a)+u(a b)+u(c)+u(a c)]>} \\
{[u(a)+u(a c)+u(b)+u(a b)] .}
\end{gathered}
$$

After canceling on both sides, it is found that $u(c)>u(b)$, contradicting the earlier 
conclusion that $u(b)>u(c)$ from (A1) and (A5). Similarly, with the substitutions from (A4), inequality (A6) can be rewritten as

$$
\begin{gathered}
{[u(a)+u(a b)+u(c)+u(a c)]>} \\
{[u(a)+u(a c)+u(a)+u(a b)] .}
\end{gathered}
$$

After canceling on both sides, it is found that $u(c)>u(a)$, contradicting the earlier conclusion that $u(a)>u(c)$ from (A1) and (A4). Therefore, EBA cannot predict the compromise effect.

Appendix B: Proof that the componential context theory cannot explain similarity effects.

Consider a choice set consisting of three cameras labeled $A, B$, and $D$. $A$ is a high-quality camera with many high-quality features and is expensive; $B$ is a low-quality camera with no extra features and is very cheap. Camera $D$ is a slightly higher-quality camera than $A$; it has more quality features and a slightly higher price than $A$. $D$ is very similar to $A$, and both $A$ and $D$ are quite different from $B$. The similarity effect implies that $p(A \mid\{A, B\})=p(A \mid\{A, D\})=p(B \mid\{B, D\})$. But, when the three options are evaluated together, either $p(B \mid\{A, B, D\})>p(A \mid\{A, B, D\})$ or $p(B \mid\{A, B, D\})>p(D \mid\{A, B, D\})$. The proof that the componential context theory cannot predict the similarity effect can be demonstrated with the first of the two triadic choices.

The componential context theory is based on the idea that people consider the advantages of one option over those of another. Camera $A$ has a higher-quality advantage over $B$ and camera $B$ has a higher-price advantage over $A$. The quality advantage of $A$ over $B$ is denoted $a d v(A, B)$ and the price advantage of $B$ over $A$ is denoted $a d v(B, A)$. For triadic choice sets, the model assumes:

$$
\begin{gathered}
p(A \mid\{A, B, D\})=F[V(A \mid\{A, B, D\}), \\
V(B \mid\{A, B, D\}), V(D \mid\{A, B, D\})]
\end{gathered}
$$

where $F$ is an increasing function of the first argument and a decreasing function of the second two. Furthermore:

$$
\begin{gathered}
V(A \mid\{A, B, D\})= \\
\sum_{k} \beta_{k} v_{k}(A)+\theta[R(A, B)+R(A, D)]
\end{gathered}
$$

where $\sum_{k} \beta_{k} v_{k}(A)=v(A)$ represents the value $v$ of option $A$ neglecting advantages of other options and:

$$
\begin{array}{r}
R(A, B)=\frac{a d v(A, B)}{a d v(A, B)+d i s(A, B)}= \\
\frac{\sum_{k} a d v_{k}(A, B)}{\sum_{k} a d v_{k}(A, B)+\sum_{k} d i s_{k}(A, B)},
\end{array}
$$

where $a d v_{k}(A, B)=v_{k}(A)-v_{k}(B)$ if $A$ has a positive advantage over $B$, and zero otherwise, and $\operatorname{dis}_{k}(A, B)=\delta\left[v_{k}(B)-v_{k}(A)\right]$ if option $A$ has a disadvantage over $B$, and zero otherwise, and where $\delta$ is a convex function consistent with loss aversion so that the value for the disadvantage of $A$ over $B$ is larger than the corresponding advantage of $B$ over $A$. Convexity is required to explain the compromise effect (Tversky and Simonson 1993).

The fact that the binary choices are all equal implies: $a d v(B, D)=a d v(D, B)$ and $v(B)=v(D) ; a d v(B, A)=a d v(A, B)$ and $v(A)$ $=v(B) ; \quad a d v(D, A)=a d v(A, D)$ and $v(A)$ $=v(D)$.

For the similarity effect, as described above, the largest advantage on price occurs between $B$ and $D$, the next largest advantage occurs between $B$ and $A$, and the smallest advantage occurs between $A$ and $D$. That is:

(B4) $a d v(B, D)>a d v(B, A)>a d v(A, D)$.

To explain the similarity effect we must obtain

$$
V(B \mid\{A, B, D\})>V(A \mid\{A, B, D\})
$$

and because

$$
\begin{aligned}
& \frac{a d v(B, A)}{a d v(B, A)+\operatorname{dis}(B, A)}- \\
& \frac{a d v(A, B)}{a d v(A, B)+\operatorname{dis}(A, B)}=0
\end{aligned}
$$

(B5) is true when 


$$
\begin{gathered}
\frac{a d v(B, D)}{\operatorname{adv}(B, D)+\operatorname{dis}(B, D)}> \\
\frac{a d v(A, D)}{\operatorname{adv}(A, D)+\operatorname{dis}(A, D)}, \\
\text { or } \frac{\operatorname{dis}(A, D)}{\operatorname{adv}(A, D)}>\frac{\operatorname{dis}(B, D)}{a d v(B, D)} .
\end{gathered}
$$

But if $a d v(B, D)>a d v(A, D)$, as in (B4), this equation must be false for convex $\delta$ functions. Thus, the componential context model cannot predict the similarity effect.

\section{Appendix C: Proof that mixed logit models} satisfy regularity.

Assume that $X$ is a complete set of options and $Y$ is a subset of $X(Y \subseteq X)$, that is $Y=\left\{A_{1}, \ldots, A_{m}\right\}$ and $X=\left\{A_{1}, \ldots, A_{n}\right\}$ with $n \geq m$. Define $L\left(A_{\mathrm{i}} \mid Y ; \beta\right)$ as the probability that option $A_{\mathrm{i}}$ is chosen from a set $Y$ given a fixed set of coefficients $\beta$. For example, $L$ may be defined by a mixed logit model with random coefficients $\beta$ (see for example, McFadden and Train, 2000). Assume that $L\left(A_{\mathrm{i}} \mid Y ; \beta\right)$ satisfies regularity. In other words, given $Y \subseteq X$, it is assumed that $L\left(A_{\mathrm{i}} \mid Y ; \beta\right)-$ $L\left(A_{\mathrm{i}} \mid X ; \beta\right)>0$ for every $\beta$. Then it follows that $p\left(A_{i} \mid Y\right)$ is given by a probability mixture of $L\left(A_{\mathrm{i}} \mid Y ; \beta\right)$ as defined by the integral over the density $f$ :

$$
p\left(A_{i} \mid Y\right)=\int L\left(A_{i} \mid Y ; \beta\right) \cdot f(\beta) d \beta .
$$

Then the difference

$$
\begin{gathered}
p\left(A_{i} \mid Y\right)-p\left(A_{i} \mid X\right)= \\
\int L\left(A_{i} \mid Y ; \beta\right) \cdot f(\beta) d \beta-\int L\left(A_{i} \mid X ; \beta\right) \cdot f(\beta) d \beta= \\
\int\left[L\left(A_{i} \mid Y ; \beta\right)-L\left(A_{i} \mid X ; \beta\right)\right] \cdot f(\beta) d \beta>0
\end{gathered}
$$

is always positive, which implies that $p\left(A_{i} \mid Y\right)>p\left(A_{i} \mid X\right)$. Therefore the mixed logit model satisfies regularity.

Appendix D: Example of how the mixed logit model can explain violations of weak stochastic transitivity.
Assume that $Y$ is a set of options $Y=\left\{A_{1}, \ldots, A_{m}\right\}$, for instance a number of college applicants following Tversky's (1969) example. Each candidate $i$ is described by three attribute values $x_{i k}$, intellectual stability $(k=1)$, emotional stability $(k=2)$, and social facility $(k=3)$. Suppose, the first candidate has the attribute values $x_{11}=66, x_{12}=90$, and $x_{13}=85$, the second candidate has the values $x_{21}=78, x_{22}=70$, and $x_{23}=55$, and the third candidate has the values $x_{31}=90, x_{32}=32$, and $x_{33}=4$. We can apply the mixed logit model as defined by equation 7 , such that the choice probability when choosing between the first and second candidate is

$p\left(A_{1} \mid\left\{A_{1}, A_{2}\right\}\right)=\frac{\exp \left(\sum_{k} \beta_{k q} \cdot x_{1 k}\right)}{\exp \left(\sum_{k} \beta_{k q} \cdot x_{1 k}\right)+\exp \left(\sum_{k} \beta_{k q} \cdot x_{2 k}\right)}$.

For convenience, define $v_{i q}=\exp \left(\sum_{k} \beta_{k q} \cdot x_{i k}\right)$. Following the logic of the mixed logit model assume the vector of weights, is selected with equal probability of $1 / 3$ from the set $Q:=\left\{\left(\beta_{11}=-1, \beta_{21}=3.2, \beta_{31}=-2.6\right),\left(\beta_{12}=1\right.\right.$, $\left.\beta_{22}=-3.025, \quad \beta_{32}=2.45\right), \quad\left(\beta_{13}=0.2, \quad \beta_{23}=\right.$ $\left.\left.-0.595, \beta_{33}=0.51\right)\right\}$. Then, the probability of choosing the first candidate when comparing the first and second candidate is:

$$
\begin{gathered}
p\left(A_{1} \mid\left\{A_{1}, A_{2}\right\}\right)=\left[v_{11} /\left(v_{11}+v_{21}\right)+\right. \\
\left.v_{12} /\left(v_{12}+v_{22}\right)+v_{13} /\left(v_{13}+v_{23}\right)\right] / 3 \\
=\left[e^{1} /\left(e^{1}+e^{3}\right)+e^{2} /\left(e^{2}+e^{1}\right)+\right. \\
\left.e^{3} /\left(e^{3}+e^{2}\right)\right] / 3=0.53
\end{gathered}
$$

Correspondingly, the probability of choosing the second candidate when comparing the second and third candidate can be determined, so that $p\left(A_{2} \mid\left\{A_{2}, A_{3}\right\}\right)=0.53$ results. Finally, when comparing the first and the third candidate the probability $p\left(A_{1} \mid\left\{A_{1}, A_{3}\right\}\right)=.47$ results, which violates weak stochastic transitivity.

Appendix E: Proof that the generalized extreme value model satisfies weak stochastic transitivity.

Assume that $Y$ is a set of options $Y=\left\{A_{1}, \ldots, A_{m}\right\}$. The generalized extreme 
value model defines the binary choice probability as follows:

$$
\begin{gathered}
p\left(A_{i} \mid\left\{A_{i}, A_{j}\right\}\right)= \\
\frac{\exp \left(\beta X_{i} / \theta_{i j}\right)}{\exp \left(\beta X_{i} / \theta_{i j}\right)+\exp \left(\beta X_{j} / \theta_{i j}\right)},
\end{gathered}
$$

where $X$ is a vector of attributes, $\beta$ is a vector of weights assigned to the attributes, and $\theta$ is as free similarity parameter that depends on the similarity between the pair of options for each choice set and that can account for violations of IIA. Note that

$$
\begin{gathered}
p\left(A_{i} \mid\left\{A_{i}, A_{j}\right\}\right)>.50 \rightarrow p\left(A_{i} \mid\left\{A_{i}, A_{j}\right\}\right) / p\left(A_{j} \mid\left\{A_{i}, A_{j}\right\}\right) \\
=\frac{\exp \left(\beta X_{i} / \theta_{i j}\right)}{\exp \left(\beta X_{j} / \theta_{i j}\right)}=\rightarrow \beta X_{i}>\beta X_{j} .
\end{gathered}
$$

Therefore if

$$
p\left(A_{i} \mid\left\{A_{i}, A_{j}\right\}\right)>.50 \text { and } p\left(A_{j} \mid\left\{A_{j}, A_{k}\right\}\right)>.50,
$$

then

$$
\begin{gathered}
\beta X_{i}>\beta X_{j} \text { and } \beta X_{j}>\beta X_{k} \rightarrow \beta X_{i}>\beta X_{k} \rightarrow \\
p\left(A_{i} \mid\left\{A_{i}, A_{k}\right\}\right)>.50 .
\end{gathered}
$$

\section{REFERENCES}

Ariely, Dan, and Thomas S. Wallsten. 1995. "Seeking Subjective Dominance in Multidimensional Space: An Exploration of the Asymmetric Dominance Effect." Organizational Behavior and Human Decision Processes, 63(3): 223-32.

Aumann, Robert J. 1962. "Utility Theory Without the Completeness Axiom." Econometrica, 30(3): 445-62.

Ballinger, T. Parker, and Nathaniel T. Wilcox. 1997.

"Decisions, Error and Heterogeneity." Economic Journal, 107(443): 1090-1105.

Bar-Hillel, Maya, and Avishai Margalit. 1988. "How Vicious are Cycles of Intransitive Choice?" Theory and Decision, 24(2): 119-45.

Becker, Gordon, Morris H. Degroot, and Jacob Marschak. 1963. "Probabilities of Choices Among Very Similar Objects: An Experiment to Decide Between Two Models." Behavioral Science, 8(4): 306-11.

Bell, David E. 1982. "Regret in Decision Making Under Uncertainty." Operations Research, 30(5): 961-81.

Berry, Steven T. 1994. "Estimating Discrete-Choice Models of Product Differentiation." RAND Journal of Economics, 25(2): 242-62.

Berry, Steven T., James Levinsohn, and Ariel Pakes. 1995. "Automobile Prices in Market Equilibrium." Econometrica, 63(4): 841-90.

Berry, Steven, James Levinsohn, and Ariel Pakes. 1999. "Voluntary Export Restraints on Automobiles: Evaluating a Trade Policy." American Economic Review, 89(3): 400-430.
Birnbaum, Michael H., Jamie N. Patton, and Melissa K. Lott. 1999. "Evidence Against Rank-Dependent Utility Theories: Tests of Cumulative Independence, Interval Independence, Stochastic Dominance, and Transitivity." Organizational Behavior and Human Decision Processes, 77(1): 44-83.

Bock, Richard D., and Lyle V. Jones. 1968. The Measurement and Prediction of Judgment and Choice. San Francisco: Holden-Day.

Brownstone, David and Kenneth E. Train. 1999. "Forecasting New Product Penetration with Flexible Substitution Patterns." Journal of Econometrics, 89(1-2): 109-29.

Budescu, David V., and Wendy Weiss. 1987. "Reflection of Transitive and Intransitive Preferences: A Test of Prospect Theory." Organizational Behavior and Human Decision Processes, 39(2): 184-202.

Busemeyer, Jerome R. 1985. "Decision Making Under Uncertainty: A Comparison of Simple Scalability, Fixed-Sample, and Sequential-Sampling Models." Journal of Experimental Psychology: Learning, Memory, and Cognition, 11(3): 538-64.

Busemeyer, Jerome R., and Adele Diederich. 2002. "Survey of Decision Field Theory." Mathematical Social Sciences, 43(3): 345-70.

Busemeyer, Jerome R., and James T. Townsend. 1993. "Decision Field Theory: A Dynamic-Cognitive Approach to Decision Making in an Uncertain Environment." Psychological Review, 100(3): 432-59.

Busemeyer, Jerome R., Ethan Weg, Rachel Barkan, Xuyang Li, and Zhengping Ma. 2000. "Dynamic and Consequential Consistency of Choices Between Paths of Decision Trees." Journal of Experimental Psychology: General, 129(4): 530-45.

Camerer, Colin F. 1989. "An Experimental Test of Several Generalized Utility Theories." Journal of Risk and Uncertainty, 2(1): 61-104.

Chu, Yun-Peng, and Ruey-Ling Chu. 1990. "The Subsidence of Preference Reversals in Simplified and Marketlike Experimental Settings: A Note." American Economic Review, 80(4): 902-11.

Cohen, Michele, and Jean-Yves Jaffray. 1988. "Is Savage's Independence Axiom a Universal Rationality Principle?" Behavioral Science, 33(1): 38-47.

Coombs, Clyde H. 1958. "On the Use of Inconsistency of Preferences in Psychological Measurement." Journal of Experimental Psychology, 55(1): 1-7.

Coombs, Clyde H., and Dean G. Pruitt. 1961. "Some Characteristics of Choice Behavior in Risky Situations." Annals of the New York Academy of Sciences, 89(5): 784-94.

Cubitt, Robin P., and Robert Sugden. 2001. "On Money Pumps." Games and Economic Behavior, 37(1): 121-60.

Davidson, Donald, and Jacob Marschak. 1959. "Experimental Tests of a Stochastic Decision Theory." In Measurement: Definitions and Theories, ed. West C. Churchman and Philburn Ratoosh. New York: Wiley, 233-69.

Davidson, Donald, John Charles C. McKinsey, and Patrick Suppes. 1955. "Outlines of a Formal Theory of Value, I." Philosophy of Science, 22(2): 140-60.

Davis, John M. 1958. "The Transitivity of Preferences." Behavioral Science, 3(1): 26-33. 
Debreu, Gerard. 1958. "Stochastic Choice and Cardinal Utility." Econometrica, 26(3): 440-44.

Debreu, Gerard. 1960. "Review of R. D. Luce, Individual Choice Behavior: A Theoretical Analysis." American Economic Review, 50(1): 186-88.

Dhar, Ravi, Stephen M. Nowlis, and Steven J. Sherman. 2000. "Trying Hard or Hardly Trying: An Analysis of Context Effects in Choice." Journal of Consumer Psychology, 9(4): 189-200.

Domencich, Tom, and Daniel L. McFadden. 1975. Urban Travel Demand: A Behavioral Analysis. Amsterdam: North-Holland.

Edwards, Ward. 1954. "The Theory of Decision Making." Psychological Bulletin, 51(4): 380-417.

Edwards, Ward. 1961. "Behavioral Decision Theory." Annual Review of Psychology, 12: 473-98.

Falmagne, Jean Claude, and Geoffrey Iverson. 1979. "Conjoint Weber Laws and Additivity." Journal of Mathematical Psychology, 20(2): 164-83.

Fishburn, Peter C. 1982. "Nontransitive Measurable Utility." Journal of Mathematical Psychology, 26(1): $31-67$.

Gigerenzer, Gerd. 1991. "How to Make Cognitive Illusions Disappear: Beyond 'Heuristics and Biases'." In European Review of Social Psychology, Vol. 2, ed. Wolfgang Stroebe and Miles Hewstone. New York: Wiley, 83-115.

Gigerenzer, Gerd. 1996a. "Rationality: Why Social Context Matters." In Interactive Minds: Life-Span Perspectives on the Social Foundation of Cognition, ed. Paul B. Baltes and Ursula M. Staudinger. Cambridge: Cambridge University Press, 319-46.

Gigerenzer, Gerd. 1996b. "On Narrow Norms and Vague Heuristics: A Reply to Kahneman and Tversky." Psychological Review, 103(3): 592-96.

Gigerenzer, Gerd, and Daniel G. Goldstein. 1996. "Reasoning the Fast and Frugal Way: Models of Bounded Rationality." Psychological Review, 103(4): 650-69.

Gigerenzer, Gerd, and Reinhard Selten, eds. 2001. Bounded Rationality: The Adaptive Toolbox. Cambridge: MIT Press.

Gonzalez-Vallejo, Claudia. 2002. "Making Trade-Offs: A Probabilistic and Context-Sensitive Model of Choice Behavior." Psychological Review, 109(1): 137-55.

Green, Jerry R., and Bruno Jullien. 1989. "Ordinal Independence in Nonlinear Utility Theory: Erratum." Journal of Risk and Uncertainty, 2(1): 119.

Greene, William H. 2000. Econometric Analysis. Upper Saddle River, N.J.: Prentice-Hall.

Grether, David M., and Charles R. Plott. 1979. "Economic Theory of Choice and the Preference Reversal Phenomenon." American Economic Review, 69(4): 623-38.

Grice, Paul H. 1975. "Logic and Conversation." In Syntax and Semantics 3: Speech Acts, ed. Peter Cole and Jerry L. Morgan. New York: Academic Press, 43-58.

Grice, Paul H. 1989. Studies in the Way of Words. Cambridge: Harvard University Press.

Griswold, Betty J., and R. Duncan Luce. 1962. "Choices among Uncertain Outcomes: A Test of a Decomposition and Two Assumptions of Transitivity."
American Journal of Psychology, 75(1): 35-44.

Hammond, Kenneth R. 1996. Human Judgment and Social Policy. New York: Oxford University Press.

Harbaugh, William T., Kate Krause, and Timothy R. Berry. 2001. "GARP for Kids: On the Development of Rational Choice Behavior." American Economic Review, 91(5): 1539-45.

Harless, David W., and Colin F. Camerer. 1994. "The Predictive Utility of Generalized Expected Utility Theories." Econometrica, 62(6): 1251-89.

Hausman, Jerry A., and David A. Wise. 1978. "A Conditional Probit Model for Qualitative Choice: Discrete Decisions Recognizing Interdependence and Heterogeneous Preferences." Econometrica, 46(2): 403-26.

Heath, Timothy B., and Subimal Chatterjee. 1995.

"Asymmetric Decoy Effects on Lower-Quality versus Higher-Quality Brands: Meta-Analytic and Experimental Evidence." Journal of Consumer Research, 22(3): 268-84.

Hensher, David A. 1986. "Dimensions of Automobile Demand: An Overview of an Australian Research Project." Environment and Planning A, 18(10): 1339-74.

Hensher, David A., and William H. Greene. 2003. "The Mixed Logit Model: The State of Practice." Transportation, 30(2): 133-76.

Hey, John D. 2001. "Does Repetition Improve Consistency?" Experimental Economics, 4(1): 5-54.

Hey, John D., and Chris Orme. 1994. "Investigating Generalizations of Expected Utility Theory Using Experimental Data." Econometrica, 62(6): 1291-1326.

Highhouse, Scott. 1996. "Context-Dependent Selection: The Effects of Decoy and Phantom Job Candidates." Organizational Behavior and Human Decision Processes, 65(1): 68-76.

Hilton, Denis J. 1995. "The Social Context of Reasoning: Conversational Inference and Rational Judgment." Psychological Bulletin, 118(2): 248-71.

Hong, Chew Soo, Edi Karni, and Zvi Safra. 1987. "Risk Aversion in the Theory of Expected Utility with Rank Dependent Probabilities." Journal of Economic Theory, 42(2): 370-81.

Huber, Joel, John W. Payne, and Christopher Puto. 1982. "Adding Asymmetrically Dominated Alternatives: Violations of Regularity and the Similarity Hypothesis." Journal of Consumer Research, 9(1): 90-98.

Huber, Joel, and Christopher Puto. 1983. "Market Boundaries and Product Choice: Illustrating Attraction and Substitution Effects." Journal of Consumer Research, 10(1): 31-44.

Keeney, Ralph L., and Howard Raiffa. 1976. Decisions with Multiple Objectives: Preferences and Value Tradeoffs. New York: Cambridge University Press.

Krantz, David H. 1967. "Rational Distance Functions for Multidimensional Scaling." Journal of Mathematical Psychology, 4(2): 226-45.

Leland, Jonathan W. 1994. "Generalized Similarity Judgments: An Alternative Explanation for Choice Anomalies." Journal of Risk and Uncertainty, 9(2): 151-72.

Lindman, Harold R., and James Lyons. 1978. "Stimulus Complexity and Choice Inconsistency 


\section{Rieskamp, Busemeyer, and Mellers: Extending the Bounds of Rationality}

Among Gambles.” Organizational Behavior and Human Decision Processes, 21(2): 146-59.

Linhart, Heinz, and Walter Zucchini. 1986. Model Selection. New York: Wiley.

Loomes, Graham, and Robert Sugden. 1982. "Regret Theory: An Alternative Theory of Rational Choice under Uncertainty." Economic Journal, 92(368): 805-24.

Loomes, Graham, and Robert Sugden. 1995. "Incorporating a Stochastic Element into Decision Theories." European Economic Review, 39(3-4): 641-48.

Lopes, Lola L. 1996. "When Time Is of the Essence: Averaging, Aspiration, and the Short Run." Organizational Behavior and Human Decision Processes, 65(3): 179-89.

Lopes, Lola L., and Gregg C. Oden. 1991. "The Rationality of Intelligence." In Probability and Rationality: Studies on L. Jonathan Cohen's Philosophy of Science, ed. Ellery Eels and Tomasz Maruszewski. Amsterdam: Editions Rodopi, 199-223.

Luce, R. Duncan. 1956. "Semiorders and a Theory of Utility Discrimination." Econometrica, 24(2): 178-91.

Luce, R. Duncan. 1958. "A Probabilistic Theory of Choice." Econometrica, 26(2): 193-224.

Luce, R. Duncan. 1959. Individual Choice Behavior. New York: Wiley.

Luce, R. Duncan. 1990. "Rational Versus Plausible Accounting Equivalences in Preference Judgments." Psychological Science, 1(4): 225-34.

Luce, R. Duncan. 2000. Utility of Gains and Losses: Measurement-Theoretical and Experimental Approaches. Mahwah, N.J.: Lawrence Erlbaum Associates.

Luce, R. Duncan, Barbara A. Mellers, and Shi-jie Chang. 1993. "Is Choice the Correct Primitive? On Using Certainty Equivalents and Reference Levels to Predict Choices among Gambles." Journal of Risk and Uncertainty, 6(2): 115-43.

Luce, R. Duncan, and Patrick Suppes. 1965. "Preference, Utility, and Subjective Probability." In Handbook of Mathematical Psychology, Vol. 3, ed. R. Duncan Luce, Robert B. Bush, and Eugene Galanter. New York: Wiley, 249-410.

Luce, R. Duncan, and Detlof von Winterfeldt. 1994. "What Common Ground Exists for Descriptive, Prescriptive, and Normative Utility Theories?" Management Science, 40(2): 263-79.

MacCrimmon, Kenneth R. 1968. "Descriptive and Normative Implications of the Decision-Theory Postulates." In Risk and Uncertainty, ed. Karl Borch and Jan Mossin. New York: St. Martin's Press, 3-23.

Machina, Mark J. 1982. “Expected Utility’ Analysis without the Independence Axiom." Econometrica, 50(2): 277-323.

Machina, Mark J. 1985. "Stochastic Choice Functions Generated from Deterministic Preferences over Lotteries.” Economic Journal, 95(379): 575-94.

Manski, Charles F. 1977. "Structure of Random Utility Models." Theory and Decision, 8(3): 229-54.

Marley, Anthony Alfred J. 1992. "A Selective Review of Recent Characterizations of Stochastic Choice Models Using Distribution and Functional Equation
Techniques." Mathematical Social Sciences, 23(1): 5-29.

Marley, Anthony Alfred J., and Hans Colonius. 1992. "The 'Horse Race' Random Utility Model for Choice Probabilities and Reaction Times, and its Competing Risks Interpretation." Journal of Mathematical Psychology, 36(1): 1-20.

May, Kenneth O. 1954. "Transitivity, Utility, and Aggregation in Preferences Patterns." Econometrica, 22(1): 1-13.

McFadden, Daniel. 1974. "Conditional Logit Analysis of Qualitative Choice Behavior." In Frontiers in Econometrics, ed. Paul Zarembka. New York: Academic Press, 105-42.

McFadden, Daniel. 1978. "Modeling the Choice of Residential Location.” In Spatial Interaction Theory and Planning Models, ed. Anders Karlqvist, Lars Lundqvist, Folke Snickars, and Jorgen W. Weibull. New York: North-Holland, 75-96.

McFadden, Daniel. 1981. "Econometric Models of Probabilistic Choice." In Structural Analysis of Discrete Data with Economic Applications, ed. Charles F. Manski and Daniel McFadden. Cambridge: MIT Press, 198-272.

McFadden, Daniel. 1999. "Rationality for Economists?" Journal of Risk and Uncertainty, 19(1-3): 73-105.

McFadden, Daniel. 2001. "Economic Choices." American Economic Review, 91(3): 351-78.

McFadden, Daniel, and Kenneth E. Train. 2000. "Mixed MNL Models for Discrete Response." Journal of Applied Econometrics, 15(5): 447-70.

McLean, Iain. 1995. "Independence of Irrelevant Alternatives before Arrow." Mathematical Social Sciences, 30(2): 107-26.

Mellers, Barbara A., and Karen Biagini. 1994. "Similarity and Choice." Psychological Review, 101(3): 505-18.

Mellers, Barbara A., Shi-Jie Chang, Michael H. Birnbaum, and Lisa D. Ordonez. 1992. "Preferences, Prices, and Ratings in Risky Decision Making." Journal of Experimental Psychology: Human Perception and Performance, 18(2): 347-61.

Meyer, Robert J., and Barbara E. Kahn. 1991. "Probabilistic Models of Consumer Choice Behavior." In Handbook of Consumer Behavior, ed. Thomas S. Robertson and Harold R. Kassarjian. Upper Saddle River, N.J.: Prentice Hall, 85-123.

Mishra, Sanjay, U.N. Umesh, and Donald E. Stem. 1993. "Antecedents of the Attraction Effect: An Information-Processing Approach." Journal of Marketing Research, 30(3): 331-49.

Mongin, Philippe. 2000. "Does Optimization Imply Rationality?" Synthese, 124(1): 73-111.

Montgomery, Henry. 1977. "A Study of Intransitive Preferences Using a Think-Aloud Procedure." In Decision-Making and Change in Human Affairs, ed. Helmut Jungermann and Gerard de Zeeuw. Dordrecht: Reidel, 347-64.

Morrison, William H. 1963. "Testable Conditions for Triads of Paired Comparison Choices." Psychometrika, 28(4): 369-90.

Mosteller, Frederick, and Philip Nogee. 1951. "An Experimental Measurement of Utility." Journal of Potitical Economy, 59(5): 371-404. 
von Neumann, John, and Oskar Morgenstern. 1947. Theory of Games and Economic Behavior. Princeton, N.J.: Princeton University Press.

Pan, Yigang, and Donald R. Lehmann. 1993. "The Influence of New Brand Entry on Subjective Brand Judgments." Journal of Consumer Research, 20(1): 76-86.

Pan, Yigang, Sue O'Curry, and Robert Pitts. 1995. "The Attraction Effect and Political Choice in Two Elections." Journal of Consumer Psychology, 4(1): 85-101.

Payne, John W., James R. Bettman, and Eric J. Johnson. 1988. "Adaptive Strategy Selection in Decision Making." Journal of Experimental Psychology: Learning, Memory, and Cognition, 14(3): 534-52.

Payne, John W., James R. Bettman, and Eric J. Johnson. 1993. The Adaptive Decisionmaker. Cambridge: Cambridge University Press.

Pitt, Mark A., In Jae Myung, and Shaobo Zhang. 2002. "Toward a Method of Selecting Among Computational Models of Cognition." Psychological Review, 109(3): 472-91.

Prelec, Drazen, Birger Wernerfelt, and Florian Zettelmeyer. 1997. "The Role of Inference in Context Effects: Inferring What You Want from What Is Available." Journal of Consumer Research, 24(1): 118-25.

Quiggin, John. 1982. "A Theory of Anticipated Utility." Journal of Economic Behavior and Organization, 3(4): 323-43.

Radner, Roy, and Jacob Marschak. 1954. "Note on Some Proposed Decision Criteria." In Decision Processes, ed. Robert M. Thrall, Clyde H. Coombs, and Robert L. Davis. New York: Wiley, 61-68.

Ranyard, Robert H. 1977. "Risky Decisions Which Violate Transitivity and Double Cancellation." Acta Psychologica, 41(6): 449-59.

Revelt, David, and Kenneth E. Train. 1998. "Mixed Logit with Repeated Choices: Households' Choices of Appliance Efficiency Level." Review of Economics and Statistics, 80(4): 647-57.

Rieskamp, Jörg, and Ulrich Hoffrage. 1999. "When Do People Use Simple Heuristics, and How Can We Tell?" In Simple Heuristics That Make Us Smart, ed. Gerd Gigerenzer, Peter M. Todd, and the ABC Research Group. New York: Oxford University Press, 141-67.

Rieskamp, Jörg, and Philipp E. Otto. 2006. "SSL: A Theory of How People Learn to Select Strategies." Journal of Experimental Psychology: General, 135(2): 207-36.

Roe, Robert M., Jerome R. Busemeyer, and James T. Townsend. 2001. "Multialternative Decision Field Theory: A Dynamic Connectionist Model of Decision Making.” Psychological Review, 108(2): 370-92.

Roelofsma, Peter, and Daniel Read. 2000. "Intransitive Intertemporal Choice." Journal of Behavioral Decision Making, 13(2): 161-77.

Rubinstein, Ariel. 1988. "Similarity and DecisionMaking under Risk (Is There a Utility Theory Resolution to the Allais Paradox?)" Journal of Economic Theory, 46(1): 145-53.

Rumelhart, Donald L., and James G. Greeno. 1971. "Similarity Between Stimuli: An Experimental Test of the Luce and Restle Choice Models." Journal of Mathematical Psychology, 8(3): 370-81.

Samuelson, Paul. 1953. Foundations of Economic Analysis. Cambridge: Harvard University Press.

Savage, Leonard J. 1954. The Foundations of Statistics. New York: Wiley.

Schmidt, Peter, and Robert P. Strauss. 1975. "Estimation of Models with Jointly Dependent Qualitative Variables: A Simultaneous Logit Approach." Econometrica, 43(4): 745-55.

Schoemaker, Paul J. H. 1982. "The Expected Utility Model: Its Variants, Purposes, Evidence and Limitations." Journal of Economic Literature, 20(2): 529-63.

Selten, Reinhard. 1991. "Properties of a Measure of Predictive Success." Mathematical Social Sciences, 21(2): 153-67.

Selten, Reinhard. 2001. "What Is Bounded Rationality?" In Bounded Rationality: The Adaptive Toolbox, ed. Gerd Gigerenzer and Reinhard Selten. Cambridge: MIT Press, 13-36.

Sen, Amartya. 1993. "Internal Consistency of Choice." Econometrica, 61(3): 495-521.

Shafir, Eldar B., and Robyn A. Leboeuf. 2002. "Rationality." Annual Review of Psychology, 53(1): 491-517.

Shafir, Eldar B., Daniel N. Osherson, and Edward E. Smith. 1993. "The Advantage Model: A Comparative Theory of Evaluation and Choice Under Risk." Organizational Behavior and Human Decision Processes, 55(3): 325-78.

Simon, Herbert A. 1956. "Rational Choice and the Structure of the Environment." Psychological Review, 63(2): 129-38.

Simon, Herbert A. 1983. "Alternative Visions of Rationality." In Reason in Human Affairs, ed. Herbert A. Simon. Stanford: Stanford University Press, 7-35.

Simonson, Itamar. 1989. "Choice Based on Reasons: The Case of Attraction and Compromise Effects." Journal of Consumer Research, 16(2): 158-74.

Sjoberg, Lennart. 1975. "Uncertainty of Comparative Judgments and Multidimensional Structure." Multivariate Behavioral Research, 10(2): 207-18.

Sjoberg, Lennart. 1977. "Choice Frequency and Similarity." Scandinavian Journal of Psychology, 18(2): 103-15.

Sjoberg, Lennart, and Dora Capozza. 1975. "Preference and Cognitive Structures of Italian Political Parties." Giornale Italiano di Psicologia, 2(3): 391-402.

Slovic, Paul, and Sarah Lichtenstein. 1983. "Preference Reversals: A Broader Perspective." American Economic Review, 73(4): 596-605.

Starmer, Chris. 2000. "Developments in Non-Expected Utility Theory: The Hunt for a Descriptive Theory of Choice under Risk." Journal of Economic Literature, 38(2): 332-82.

Stern, Eliahu, and Harry W. Richardson. 2005. "Behavioural Modelling of Road Users: Current Research and Future Needs." Transport Reviews, 25(2): 159-80.

Thorngate, Warren. 1980. "Efficent Decision Heuristics." Behavioral Science, 25(3): 219-25.

Thurstone, Louis L. 1927. "A Law of Comparative 
Judgment." Psychological Review, 34(4): 273-86.

Thurstone, Louis L. 1959. The Measurement of Values. Chicago: University of Chicago Press.

Train, Kenneth E. 2003. Discrete Choice Models with Simulation. Cambridge: Cambridge University Press.

Tversky, Amos. 1969. "Intransitivity of Preferences." Psychological Review, 76(1): 31-48.

Tversky, Amos. 1972a. "Choice by Elimination." Journal of Mathematical Psychology, 9(4): 341-67.

Tversky, Amos. 1972b. "Elimination By Aspects: A Theory of Choice." Psychological Review, 79(4): 281-99.

Tversky, Amos, and J. Edward Russo. 1969. "Substitutability and Similarity in Binary Choices." Journal of Mathematical Psychology, 6(1): 1-12.

Tversky, Amos, and Itamar Simonson. 1993. "Context Dependent Preferences.” Management Science, 39(10): 1179-89.

Tversky, Amos, Paul Slovic, and Daniel Kahneman. 1990. "The Causes of Preference Reversal." American Economic Review, 80(1): 204-17.

Usher, Marius, and James L. McClelland. 2004. "Loss Aversion and Inhibition in Dynamical Models of Multialternative Choice." Psychological Review,
111(3): 757-69.

Wakker, Peter, Ido Erev, and Elke U. Weber. 1994. "Comonotonic Independence: The Critical Test between Classical and Rank-Dependent Utility Theories." Journal of Risk and Uncertainty, 9(3): 195-230.

Wedell, Douglas H. 1991. "Distinguishing Among Models of Contextually Induced Preference Reversals." Journal of Experimental Psychology: Learning, Memory, and Cognition, 17(4): 767-78.

Wedell, Douglas H., and Jonathan C. Pettibone. 1996. "Using Judgments to Understand Decoy Effects in Choice." Organizational Behavior and Human Decision Processes, 67(3): 326-44.

Wernerfelt, Birger. 1995. “A Rational Reconstruction of the Compromise Effect: Using Market Data to Infer Utilities." Journal of Consumer Research, 21(4): 627-33.

von Winterfeldt, Detlof, and Ward Edwards. 1986. Decision Analysis and Behavioral Research. Cambridge: Cambridge University Press.

Yaari, Menahem E. 1987. "The Dual Theory of Choice under Risk.” Econometrica, 55(1): 95-115. 